NIST Technical Note 2074

\title{
Measuring Water Flow Rate for a Fire Hose Using a Wireless Sensor Network for Smart Fire Fighting
}

Christopher U. Brown

Gregory W. Vogl

Wai Cheong Tam 


\title{
Measuring Water Flow Rate for a Fire Hose Using a Wireless Sensor Network for Smart Fire Fighting
}

\author{
Christopher U. Brown \\ Wai Cheong Tam \\ Fire Research Division \\ Engineering Laboratory \\ Gregory W. Vogl \\ Intelligent Systems Division \\ Engineering Laboratory
}

This publication is available free of charge from:

https://doi.org/10.6028/NIST.TN.2074

November 2019

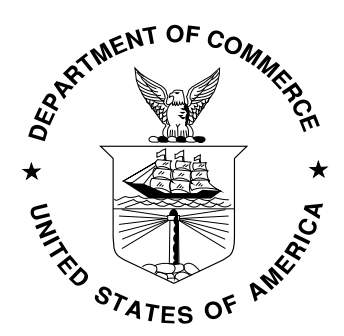

U.S. Department of Commerce

Wilbur L. Ross, Jr., Secretary

National Institute of Standards and Technology Walter Copan, NIST Director and Undersecretary of Commerce for Standards and Technology 
Certain commercial entities, equipment, or materials may be identified in this document in order to describe an experimental procedure or concept adequately. Such identification is not intended to imply recommendation or endorsement by the National Institute of Standards and Technology, nor is it intended to imply that the entities, materials, or equipment are necessarily the best available for the purpose.

The opinions, recommendations, findings, and conclusions in this publication do not necessarily reflect the views or policies of NIST or the United States Government.

National Institute of Standards and Technology Technical Note 2074

Natl. Inst. Stand. Technol. Tech. Note 2074, 34 pages (November 2019)

CODEN: NTNOEF

This publication is available free of charge from:

https://doi.org/10.6028/NIST.TN.2074 


\begin{abstract}
A wireless sensor network was created to measure water-flow rate in a fire hose. An integrated electronic piezoelectric (IEPE) accelerometer was chosen as the sensor to measure the flow rate based on the vibrations generated by water flowing through a fire hose close to the hose nozzle. These sensors are small, lightweight, and they can attach to the outside of the hose, not obstructing the water's flow path. A relationship between the dominantfrequency metric and the flow rate was applied and used to determine real-time water flow in a fire hose critical for improving fireground situational awareness. A nearly monotonic relationship of flow rate to the dominant frequency was established and then used in a custom graphical user interface for quick, real-time, visual referencing by fire personnel of flow rate in a fire hose. While more work is needed, such as improved physical robustness of the sensor-node assembly and increase robustness of the signal metric, this preliminary study showed the potential of a "smart" fire hose for improved situational awareness during a fire attack.
\end{abstract}

\title{
Key words
}

Accelerometers; fire hose; flow induced vibration; flow rate; hose vibration; dominant frequency; smart fire fighting; sensors; water flow rate measurement; wireless sensor network. 


\section{Table of Contents}

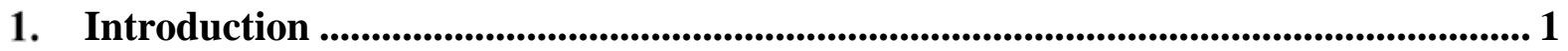

1.1. Smart Fire Fighting - Water Flow at the Fire Hose Nozzle..................................... 1

1.2. Current State of the Art .................................................................................... 2

1.3. Study Goal ..................................................................................................... 2

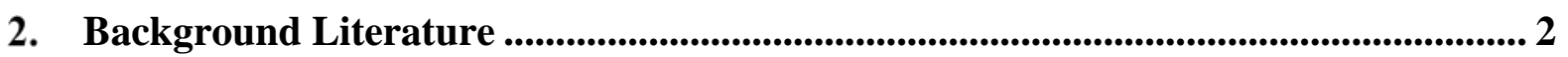

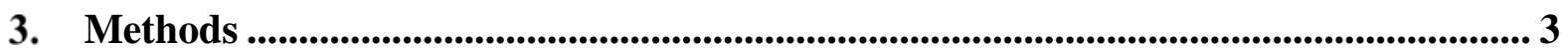

3.1. Wireless sensor network (WSN) components ................................................... 3

3.1.1. Wireless sensor network - Sensor - Accelerometer............................................ 3

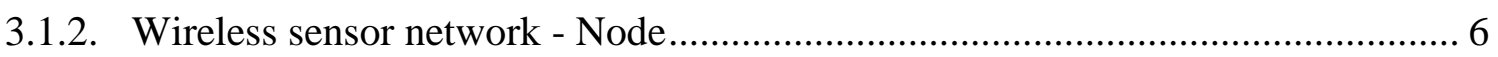

3.1.3. Wireless sensor network - Base Station ......................................................... 7

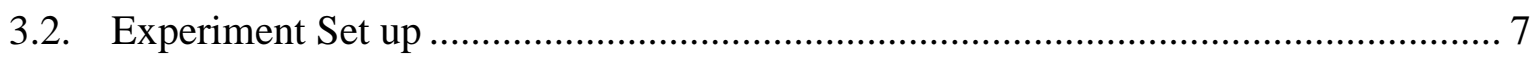

4. Results and Discussion - Test 4, Test 5, and Test 6 ...................................................... 11

4.1. Results and Discussion - Test 4, Test 5, and Test 6 - Standard Deviation of

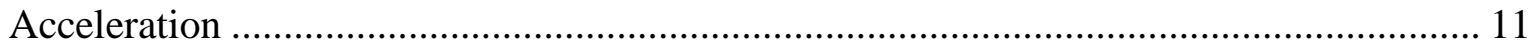

4.2. Results and Discussion - Test 4, Test 5, and Test 6 - Initial Dominant Frequency 14

4.3. Results and Discussion - Beyond Test 4, Test 5, and Test 6 - Dominant Frequency17

5. Real-Time Fire Hose Flow Rate ........................................................................... 18

6. Practical Considerations for a Nozzle Flow Meter.................................................. 22

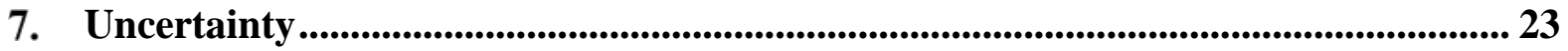

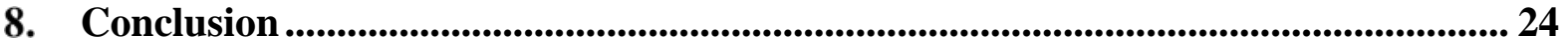

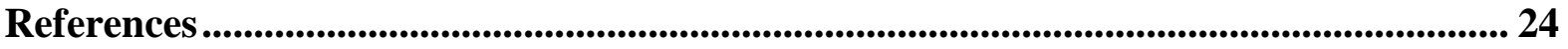




\section{List of Figures}

Fig. 1. A 'smart' sensor network can measure flow rate at the fire hose nozzle and wirelessly communicate the flow rate in real time to the IC and pump operator for decision making. .... 1 Fig. 2. The wireless sensor network components in this study: 1) The accelerometer sensor, 2) the wireless node, and 3) the base station at the laptop.

Fig. 3. The Front accelerometer attached to a base that was epoxied to the exterior fabric of the fire hose. The wireless node is inside a protective plastic box.

Fig. 4. The three accelerometer locations along the $15 \mathrm{~m}(50 \mathrm{ft})$ fire hose.......................... 4

Fig. 5. The two accelerometers at the Back and Mid locations on the concrete floor (left), and the accelerometer at the Front location outside in the grass close to the nozzle (right).......... 5

Fig. 6. The Mid accelerometer mounted to the base on the exterior fabric of the fire hose.... 5

Fig. 7. The wireless node with antenna. .................................................................... 6

Fig. 8. During testing, the wireless node was inside a protective plastic box to avoid damage.

Fig. 9. The base station attached to the laptop through a USB port. .................................. 7

Fig. 10. Nozzle, dial pressure gauge, and turbine reference flow meter at the front, or downstream, end of the fire hose.

Fig. 11. The data sampling burst cycle for a single node. Data was sampled for 0.19 seconds, every 10 seconds in the burst cycle in this study.

Fig. 12. Baseline data collected during a single sampling burst for 0.19 seconds for the noflow condition in a time-series plot.

Fig. 13. Data collected (from Test 6) for all data sampling bursts in a time-series plot for the entire water flow range.

Fig. 14. Data collected (from Test 6) for data sampling bursts for three flow rates, 458 LPM

(121 GPM), 473 LPM (125 GPM), and 488 LPM (129 GPM) in a time-series plot..... 10

Fig. 15. Data collected (from Test 6) for a single data sampling burst for 0.19 seconds for the three accelerometers at 420 LPM (111 GPM) in a time-series plot from which the standard deviation of the signal was determined.

Fig. 16. The standard deviation of acceleration versus flow rate for Test 4, Test 5, and Test 6 for the Front accelerometer.

Fig. 17. The mean standard deviation of acceleration with standard deviation bars versus flow rate for the Front accelerometer from Test 4, Test 5, and Test 6.

Fig. 18. The standard deviation of acceleration versus flow rate for the Front accelerometer for the wireless Test 4, Test 5, and Test 6 and wired Test 3.

Fig. 19. A sample of the dominant frequency based on the power spectrum. A peak can be seen around $300 \mathrm{~Hz}$.

Fig. 20. Dominant frequency versus flow rate for the Front accelerometer for the wireless Test 4, Test 5, and Test 6 .

Fig. 21. Dominant frequency versus flow rate for the Front accelerometer for the wireless Test 4, Test 5, and Test 6 and for the wired Test 3.

Fig. 22. The mean dominant frequency with standard deviation bars versus flow rate from wired Test 3 and wireless Test 4, Test 5, and Test 6.

Fig. 23. Dominant frequency with standard deviation bars versus flow rate data after modifying the data sampling parameters resulting in reduced scatter, except at zero flow where the signal noise dominated causing scatter.

Fig. 24. The GUI - Flow dashboard (left) and Frequency dashboard (right) 
Fig. 25. The Frequency dashboard for the zero-flow condition: 1) the initial settings, 2) the raw time-series signal, 3) filtering input, 4) filtered frequency, 5) dominant frequency, 6) flow rate based on the dominant frequency.

Fig. 26. The Flow dashboard for no-flow: 1) the time-series signal, 2) a bar meter for the flow rate of 0 GPM, 3) two-light indicator for flow rate...

Fig. 27. The Frequency dashboard for 100 GPM and displayed a dominant frequency of $378.6 \mathrm{~Hz}$ 20

Fig. 28. The Flow dashboard for 100 GPM with yellow colored bar meter and with one blue light illuminated.

Fig. 29. The Frequency dashboard for 164 GPM. Note the Savitzky-Golay smoothing filter reduced the two peaks seen in the raw power spectrum to one dominant frequency............ 21 Fig. 30. The Flow Panel for 164 GPM with green colored meter and with two blue lights illuminated. 


\section{Introduction}

\subsection{Smart Fire Fighting - Water Flow at the Fire Hose Nozzle}

There is an old fire service saying, "As the first line goes, so goes the fire.” Placing, and flowing water, from the initial hose line, and including all other hose lines, at a fire is very important for the success of the fire attack. The water flowing from the hoses helps cool the environment which improves the chance of survival of trapped occupants, protects the fire fighters from excessive heat, and extinguishes the fire. Therefore, hoses are simultaneously a fire fighter's and occupant's lifeline [1]. Knowing the rate at which water is flowing through those hoses is a critical part of those lifelines, in general, and situational awareness, in particular, especially if that rate is zero, which unfortunately happens.

Applying 'smart' technology to a fire hose could improve the awareness of the hose's current status and the chance of a successful fire attack. Harnessing the power of 'smart' technology to improve situational awareness of the hoses was a part of the vision of Smart Fire Fighting as documented in the Research Roadmap for Smart Fire Fighting [2]. A 'smart' system uses sensors to collect data, provides the data in an understandable format to a user, then allows the user to make a decision. Today, the users are human, but tomorrow they may include software.

Human fire fighters are the backbone of the fire service. The safety of fire fighters who risk their lives on the fireground could benefit from a smart sensor network, that could perform two tasks: determine if water is flowing at the fire hose nozzle and communicate this information back to the pump operator or incident commander (IC) at the fire engine. The smart system includes a sensor at the nozzle, wirelessly transmitting the flow rate data to the incident commander (IC), and a way to present the data to the IC (Fig. 1). The IC must be able to make quick decisions regarding the water flow for suppression activities on the fireground.

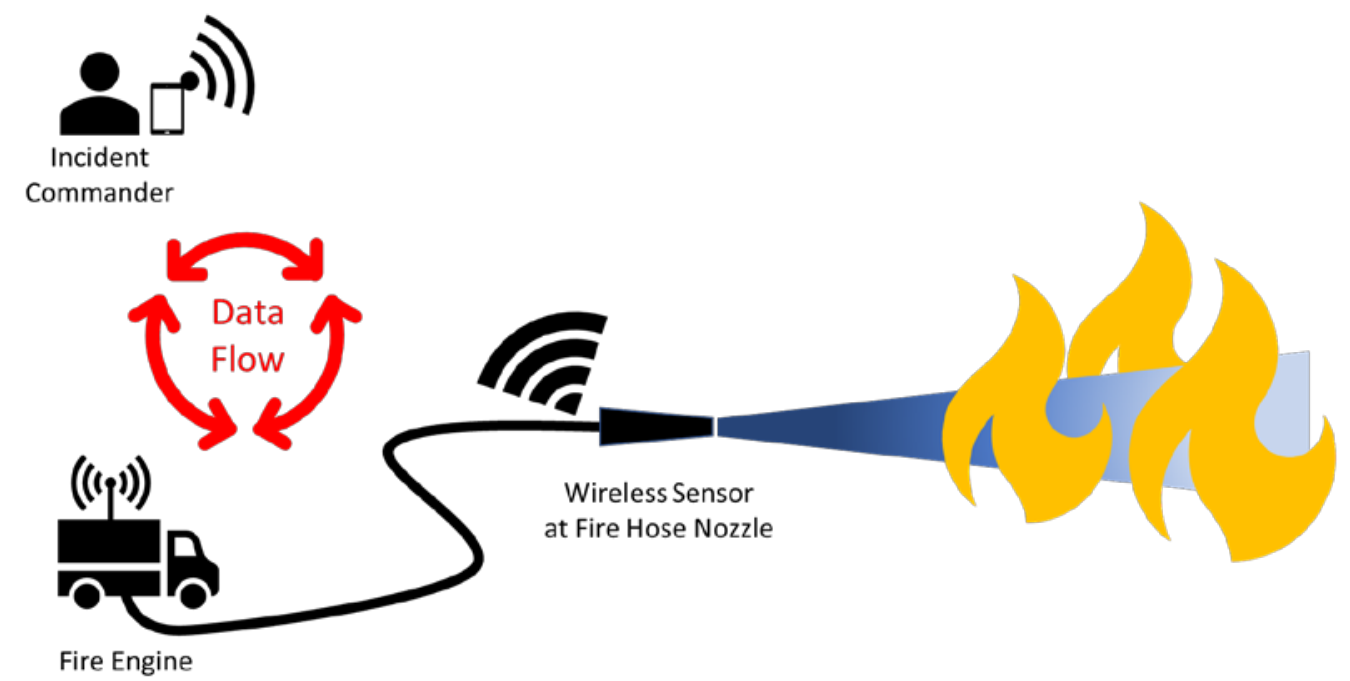

Fig. 1. A 'smart' sensor network can measure flow rate at the fire hose nozzle and wirelessly communicate the flow rate in real time to the IC and pump operator for decision making. 


\subsection{Current State of the Art}

Currently, communication between the fire fighter at the nozzle and the pump operator or IC is typically done using radios. The fire fighter at the nozzle, or his backup, should be able to communicate by radio with the pump operator or IC to provide feedback about water flow. However, this is not always possible to do with competing radio traffic, while the team is advancing the hose, and conducting suppression activities that take two hands.

Presently, water pressure measured at the fire engine's pump panel is used by the pump operator to determine if water is flowing at the hose nozzle. Fireground threats to normal water flow such as hose damage and hose blockage can make reliable decisions on water pressure misleading. A pressure loss indicated on the fire engine's pump panel may occur when water flows from the nozzle, as intended, or unintentionally through a ruptured hose. A ruptured hose can occur as a result of wear and tear, a burn hole in the hose, a leaking coupling, or from being crushed under a vehicle tire or structure debris.

Sufficient water pressure may show at the pump panel even if the hose is partially or fully blocked preventing water, or allowing too little water, from reaching the nozzle. A charged hose line advanced inside a structure could become partially blocked as a result of being crimped around a sharp corner or past a piece of furniture. A hose pinched under a door, under a piece of furniture, under a vehicle tire, or under fallen debris could also reduce water flow at the nozzle. Water flow through the hose could be fully blocked by a closed in-line valve, debris in the hose, or by a closed nozzle bale that cannot be opened by an incapacitated fire fighter.

\subsection{Study Goal}

The safest way for the IC to know that water is flowing from the hose nozzle is to have realtime water flow information sent to them. The goal of this study is to provide that information digitally by developing a wireless-sensor network to measure water flow in a fire hose. Our approach is to collect vibration data, send it to the IC's laptop, and then convert it into a flow rate based on data-derived correlations. Flow rate will be determined in real time to improve fireground situational awareness.

\section{Background Literature}

Vibrations from fluid or gas flow can occur in any relatively rigid pipe such as water, oil, and gas utility or industrial pipes. Wired sensors, including accelerometers, have been attached securely to the outside surface of rigid pipes to measure fluid or gas induced pipe vibrations to determine flow rate within the pipe in research settings as well as in the utility pipeline industry [3-16].

The advantages of wireless sensor networks have resulted in their application to rigid pipes and utility pipelines to detect flow and assess pipeline health where long distances of pipe can be checked from fewer remote locations [17-21]. Wireless technology has been applied to fire hoses. An in-line, turbine, commercial wireless flow meter is available for fire hoses 
that transmits data to a hand-held device using Bluetooth ${ }^{\circledR}$ that reports the flow rate [22]. The turbine also supplies power to the hose meter.

A detailed literature review was included in the previous technical report [23] describing past work focused on detecting vibration from flowing water in relatively rigid pipe using sensors like accelerometers [24]. Standard deviation of acceleration increased as flow rate increased in rigid pipes [8-10, 14-16]. This relationship was found to be similar for flexible fire hose at lower flow rates, from 0 LPM to at least about 300 LPM (80 GPM), however at higher flow rates, above 300 LPM (80 GPM), the standard deviation of acceleration became unpredictable, often peaking and decreasing [23]. The bell-shaped curve therefore made the standard deviation of acceleration metric not suitable as the only metric for determining the flow rate in a flexible fire hose.

For relatively rigid pipe, previous research has shown a decreasing dominant frequency with increasing flow rate $[8,13,25]$. A similar relationship was also found for flexible fire hose in our previous research [23]. Dominant frequency was therefore chosen as the primary metric to determine flow rate. Dominant frequency determined by impact testing matched the dominant frequency as determined by our flow tests. Therefore, it is possible to use this metric to determine flow rate in the fire hose in real time using a wireless sensor network.

\section{Methods}

\subsection{Wireless sensor network (WSN) components}

The wireless sensor network for this research has three main components: 1 ) the accelerometer as the sensor, 2) the wireless node, and 3) the base station (Fig. 2). The sensor collects data, the wireless node transmits the data, and the base station receives the data and passes it to a laptop for analysis.
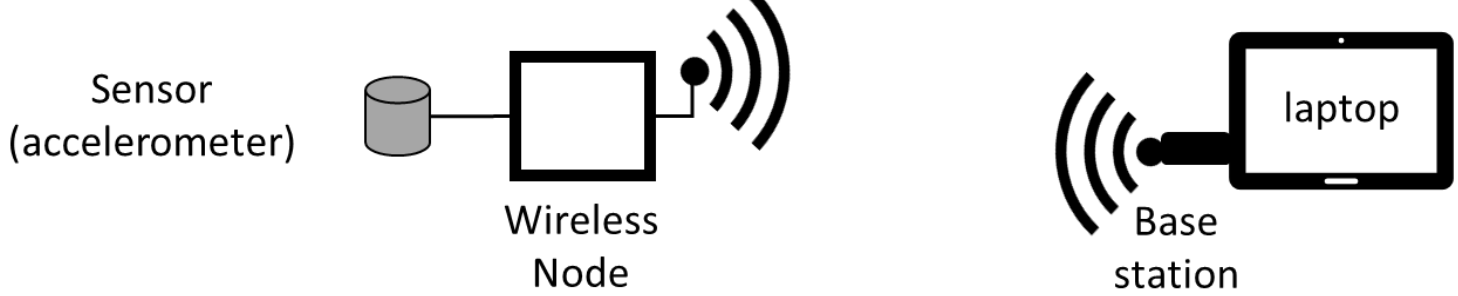

Fig. 2. The wireless sensor network components in this study: 1) The accelerometer sensor, 2) the wireless node, and 3) the base station at the laptop.

\subsubsection{Wireless sensor network - Sensor - Accelerometer}

Accelerometers measured the vibration of the hose caused by water flowing through the fire hose. Two accelerometers were used on the hose at the Front (downstream) and Back (upstream) locations for one series of tests (Test 4). Three accelerometers collected data from the Front, Mid (middle) and Back locations on the hose for the following two different series 
of tests (Test 5 and Test 6). The wired sensor network tests from the previous report were labeled as Test 1, Test 2, and Test 3 [23].

The piezoelectric accelerometers at either end of the hose (PCB model 352C33) measured acceleration and stand about $2 \mathrm{~cm}$ high mounted on a base epoxied to the exterior fabric of

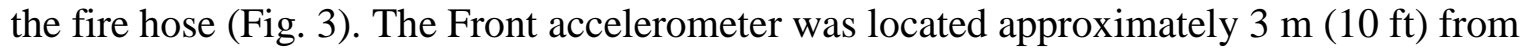
the nozzle on a section of hose laying on grass (Fig. 4 and Fig. 5). The Back accelerometer was located approximately $2.4 \mathrm{~m}(8 \mathrm{ft})$ from the hose attachment to the water source at a position where the fire hose was on the concrete floor.

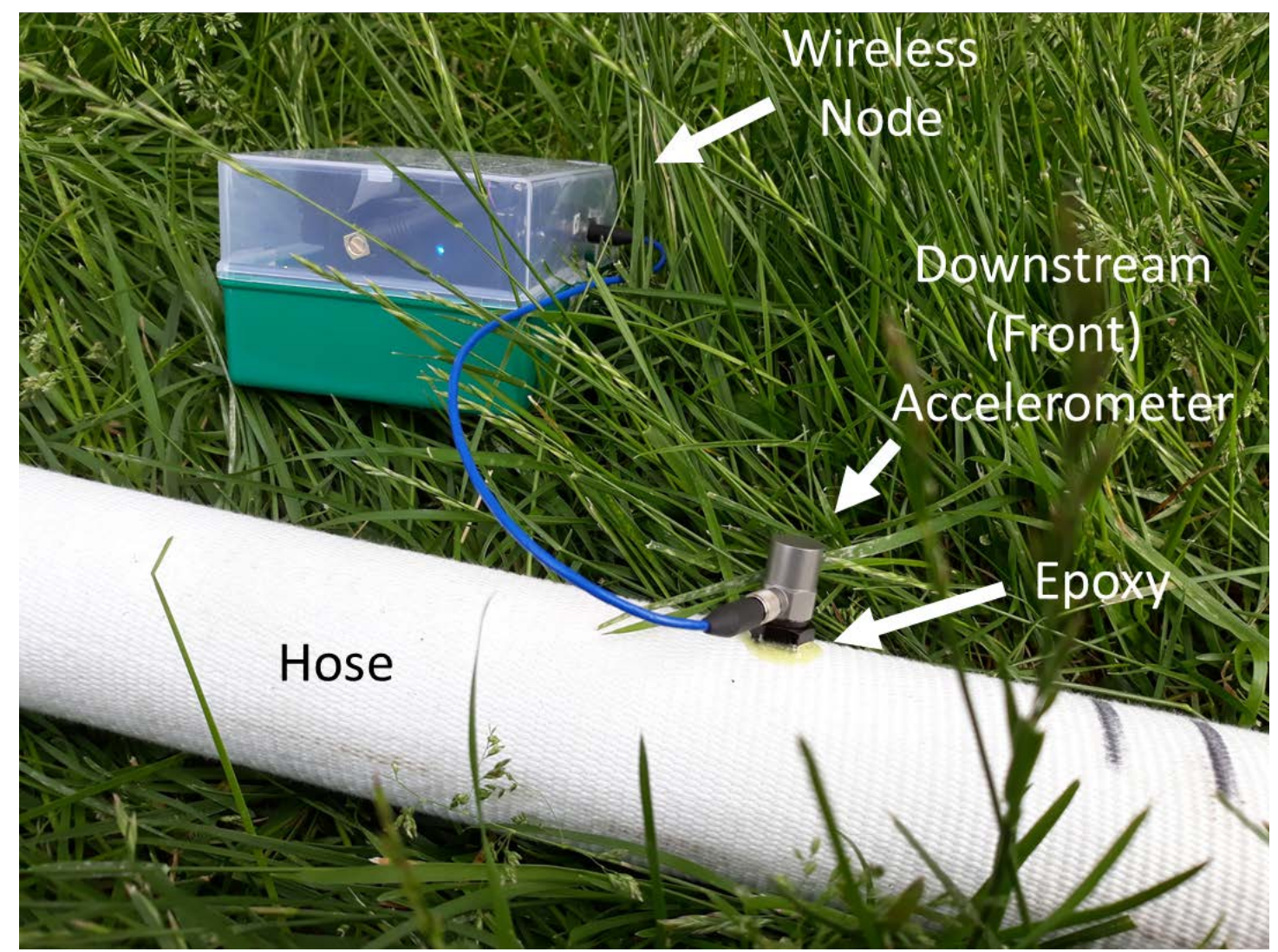

Fig. 3. The Front accelerometer attached to a base that was epoxied to the exterior fabric of the fire hose. The wireless node is inside a protective plastic box.

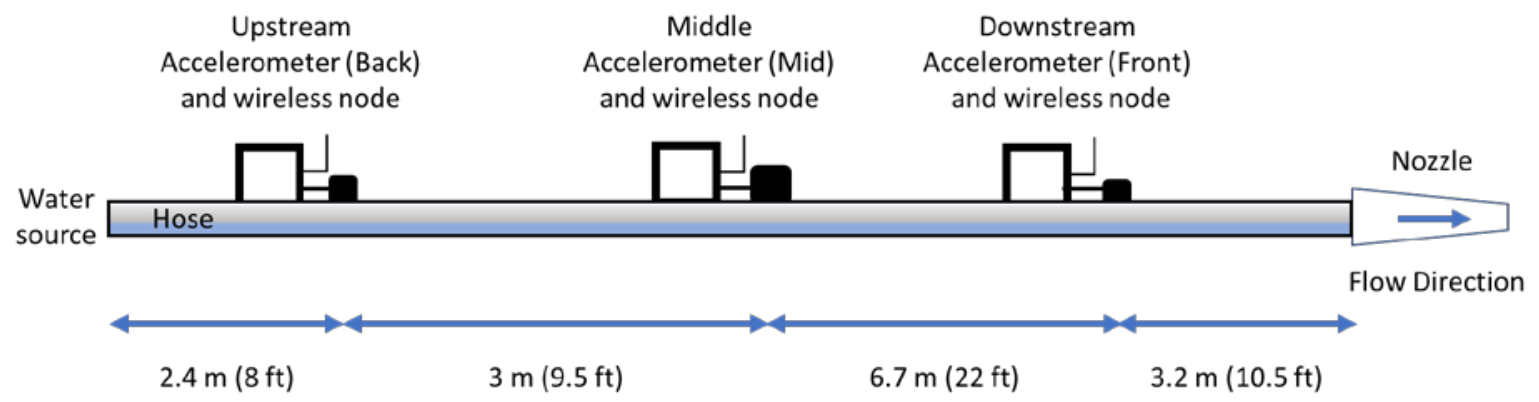

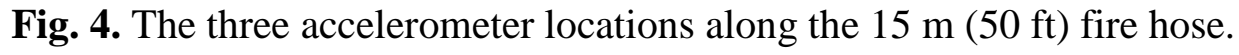



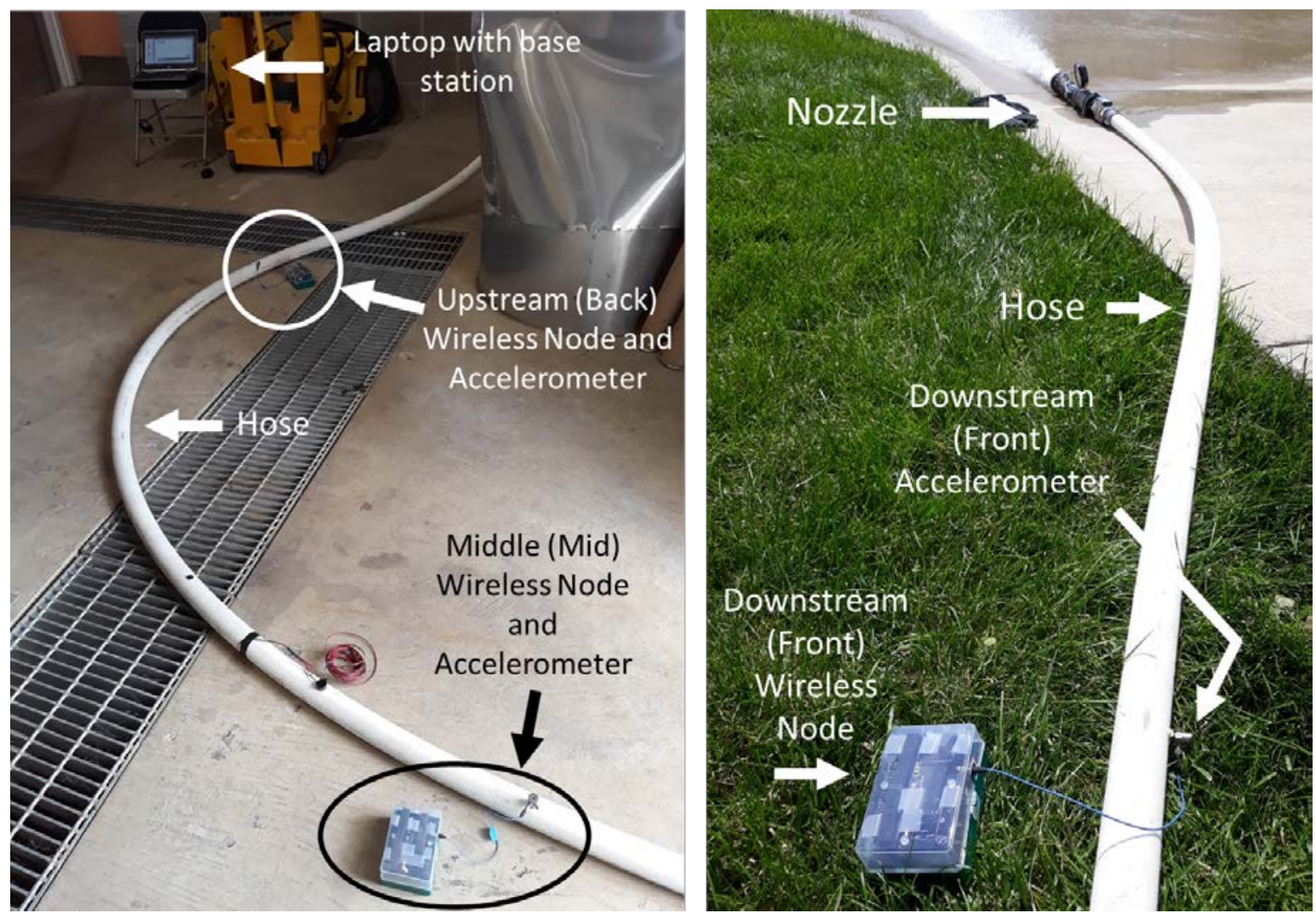

Fig. 5. The two accelerometers at the Back and Mid locations on the concrete floor (left), and the accelerometer at the Front location outside in the grass close to the nozzle (right).

The Mid accelerometer (PCB model 288D01) also measured acceleration and was about $2 \mathrm{~cm}$ high mounted in the same way to the hose (Fig. 6). The Mid accelerometer was located approximately $10 \mathrm{~m}$ (32.5 ft) from the nozzle (Fig. 4) on a section of hose that was on the concrete floor (Fig. 6). Power to the accelerometers was supplied from the wireless nodes.

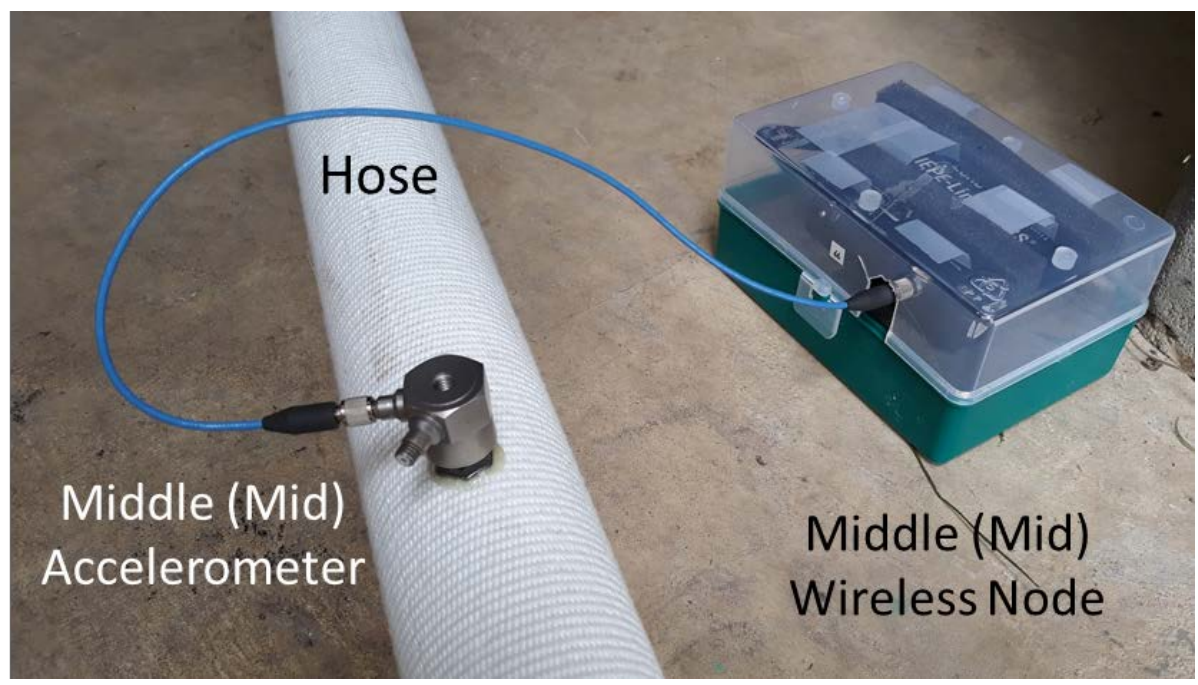

Fig. 6. The Mid accelerometer mounted to the base on the exterior fabric of the fire hose. 


\subsubsection{Wireless sensor network - Node}

The second component of the wireless sensor network was the wireless node (LORD MicroStrain IEPE-LXRS) (Fig. 7). Each accelerometer was connected to a wireless node by a coaxial cable with 10-32 connectors. Some wireless nodes may include an embedded sensor, however for this study, the same accelerometers were also used for the wired sensor network in a previous study [23].

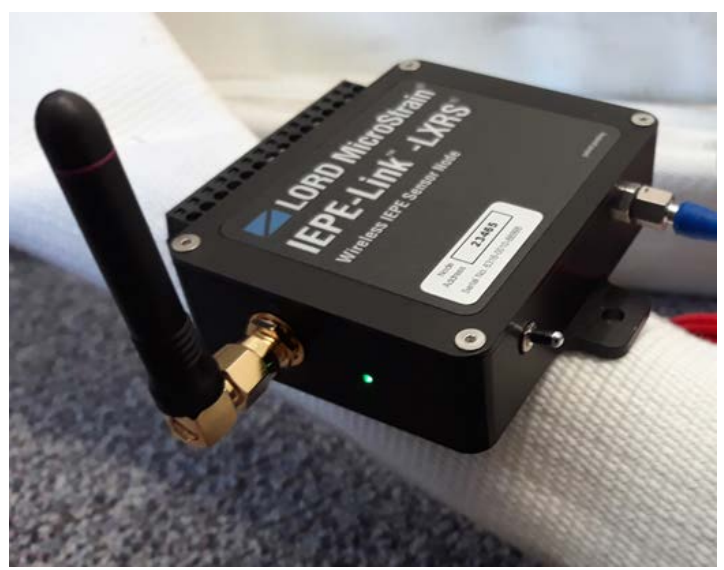

Fig. 7. The wireless node with antenna.

The number of wireless nodes used in the wireless sensor network affects the data sampling frequency, data collection time, and interval between data collection times. To meet our data collection needs, a maximum of three wireless nodes were used. The node is powered by a rechargeable battery which also powered the accelerometers. During testing in this study, the nodes were placed within a protective plastic box to prevent damage (Fig. 8). The protective plastic box did not affect the wireless signal.

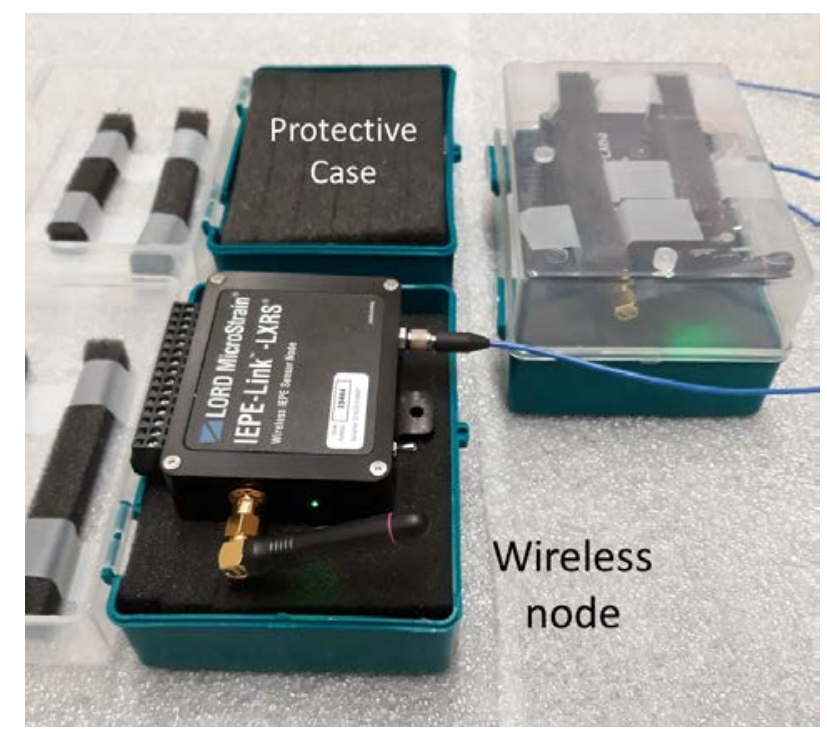

Fig. 8. During testing, the wireless node was inside a protective plastic box to avoid damage. 


\subsubsection{Wireless sensor network - Base Station}

The third component of the wireless sensor network was the base station, also called a gateway (Fig. 9). The wireless nodes communicate with the base station using radio frequency (RF) signal $(2.425 \mathrm{GHz})$ which receives and collects the sensor data. The base station in this study was connected to, and powered by, a laptop via a USB port. The base station synchronized the data from multiple wireless nodes transmitted on the same RF and passed the data to the laptop software for processing.

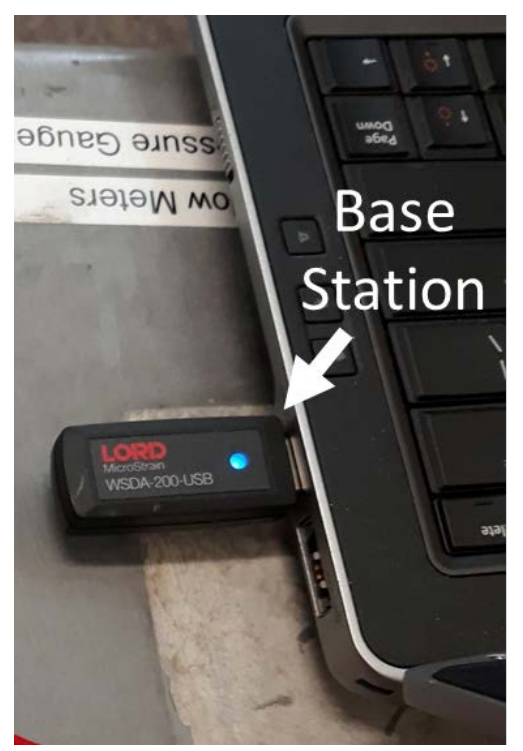

Fig. 9. The base station attached to the laptop through a USB port.

\subsection{Experiment Set up}

The commercial fire attack hose used in this study had a nominal $4.5 \mathrm{~cm}$ (1.75 in) inner

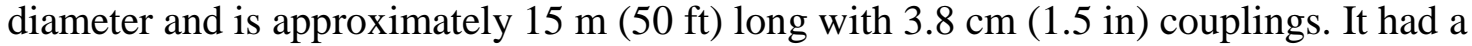
polyester inner and outer jacket with EPDM (ethylene propylene diene monomer rubber) synthetic rubber inner lining typical for a commercial fire hose attack line. Water was supplied to the hose from a building interior water supply. The maximum pressure supplied by the water source to the hose was approximately 0.6 MPa (90 psi).

A commercial turbine flow meter was used at the nozzle to measure the reference flow rate during the study. The flow meter was previously shown to provide the correct flow rate following AS/NZS 1221:1997 [26]. For a variety of reasons, the reference flow rate drifted approximately $\pm 3.8 \mathrm{LPM}(1.0 \mathrm{GPM})$ at the highest reference flow rates, but drifted less than approximately $\pm 1.9 \mathrm{LPM}(0.5 \mathrm{GPM})$ at the lower reference flow rates. For consistency, the abbreviation 'LPM' represents L/min and 'GPM' represents gallons/min for the remaining text. The turbine flow meter and a dial pressure gauge were attached between the fire hose and the nozzle (Fig. 10). There was sufficiently straight flow upstream and downstream of the commercial flow meter turbine to satisfy the manufacturer's recommendation for maintaining the flow meter accuracy. 


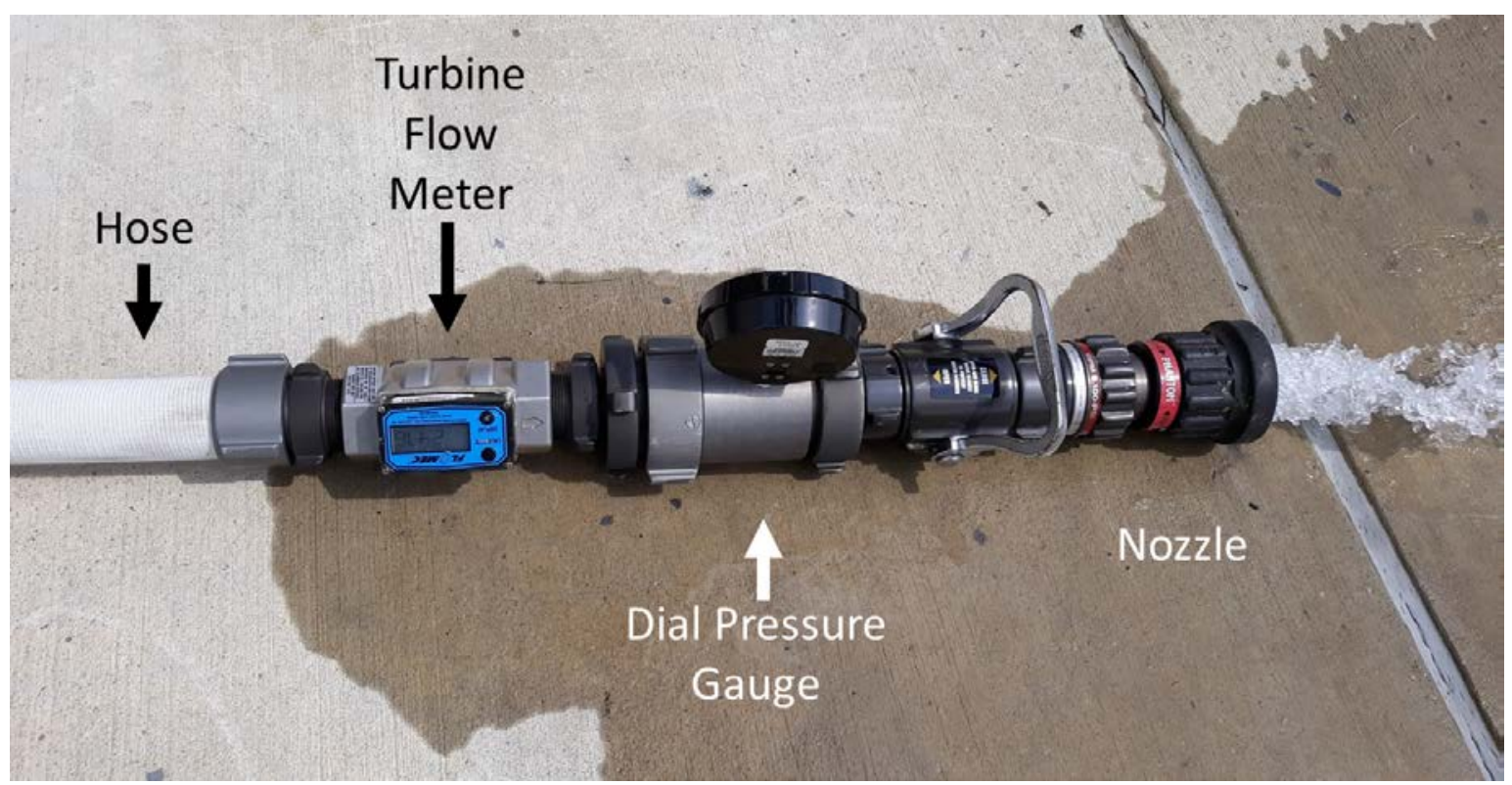

Fig. 10. Nozzle, dial pressure gauge, and turbine reference flow meter at the front, or downstream, end of the fire hose.

In the wireless sensor network used in this study, the wireless nodes sampled data in synchronized bursts and followed a burst cycle. Sampling data continuously was not an available option with the wireless nodes. The burst cycle consisted of four phases: Phase 1 the accelerometer was charged from the wireless node before the first data sampling burst; Phase 2 - at the scheduled burst time, the node started sampling data for the duration of the burst period as selected; Phase 3 - once data sampling was completed, the data was transmitted from the wireless node to the base station; Phase 4 - when transmission was completed, the node returned to its low power mode until the next scheduled burst [27].

For this study, the parameters for the burst cycle were selected based on the number of nodes in the network and the data sampling rate for the available bandwidth of the wireless sensor network. For a three-node network, and a data sampling rate of $10 \mathrm{kHz}$, data was sampled for 0.19 seconds every 10 seconds (Fig. 11). The node takes time to transmit data that depends on the amount of sampled data and the transmit rate. The transmit rate for the nodes in this study was automatically set based on the time increment between samples. The data received by the base station was passed to the software in nearly real-time acquisition. 


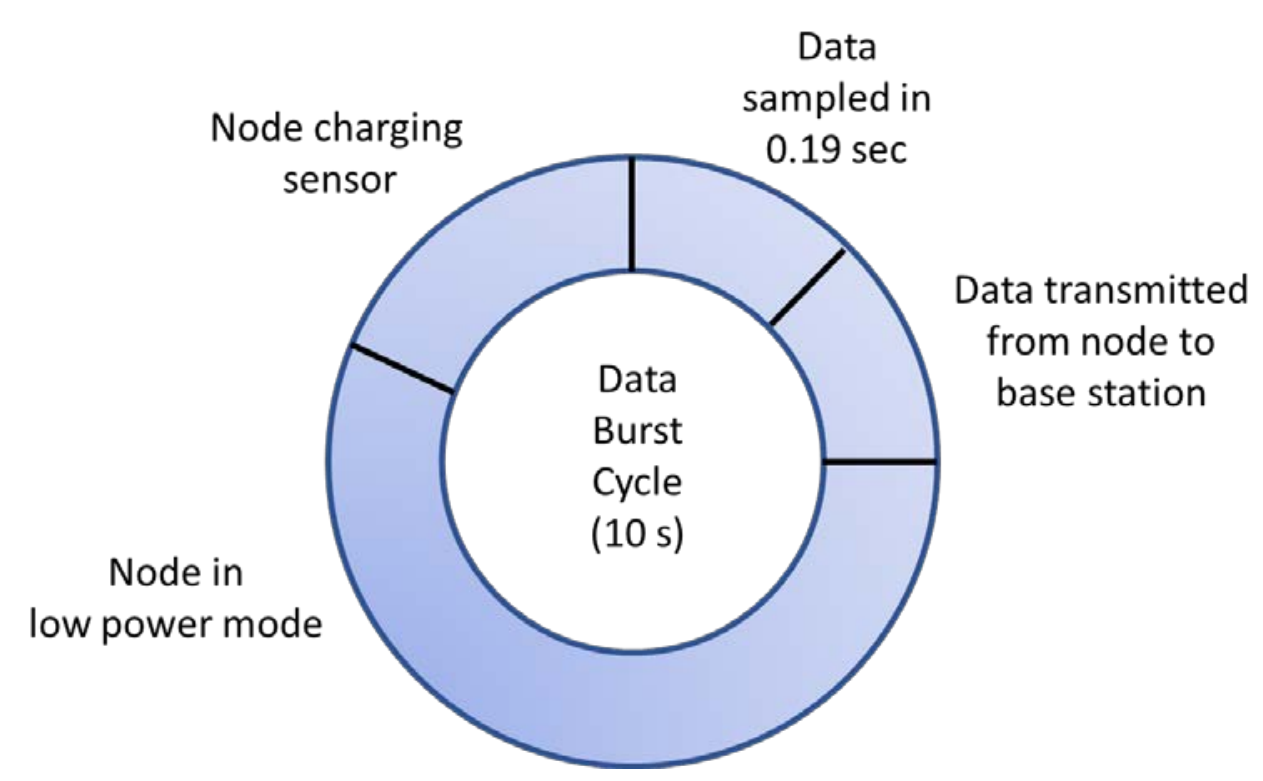

Fig. 11. The data sampling burst cycle for a single node. Data was sampled for 0.19 seconds, every 10 seconds in the burst cycle in this study.

The hose was pressurized with the nozzle closed and the dial gauge measured approximately 0.6 MPa (90 psi). Once the three sensors were attached and confirmed to be collecting vibration data, the data collection program was started and vibrations from the Back (upstream), Front (downstream), and Mid (middle) accelerometers were collected at a sampling frequency of $10 \mathrm{kHz}$. The no-flow vibrations from the three sensors were collected for five minutes. The baseline data collected indicated that the no-flow, noise vibrations were in the range of approximately $\pm 0.1 \mathrm{~m} / \mathrm{s}^{2}$ (Fig. 12).

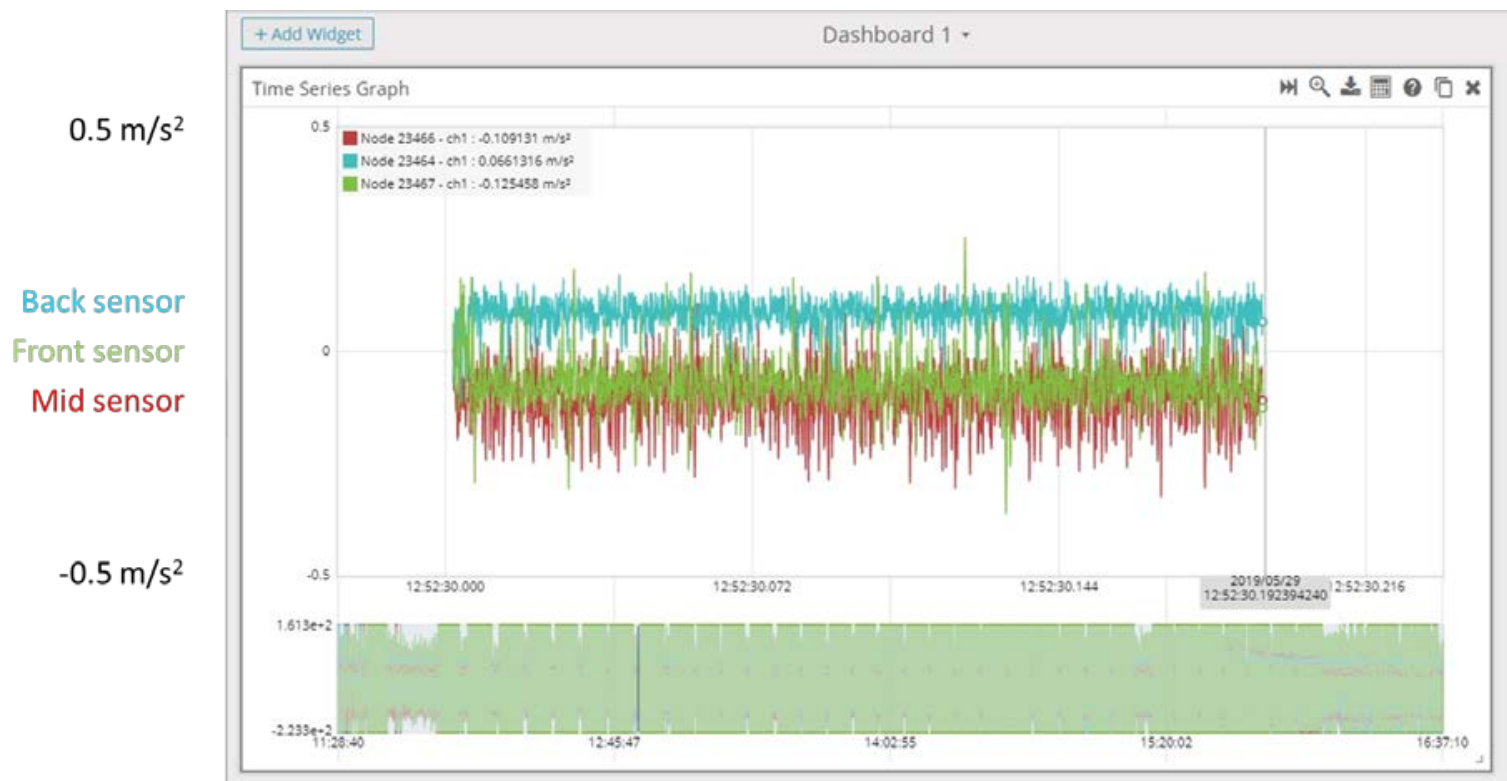

Fig. 12. Baseline data collected during a single sampling burst for 0.19 seconds for the noflow condition in a time-series plot. 
After the no-flow condition was sampled, the desired flow rate was measured using the nozzle bale to regulate the water flow. The reference flow rate was measured by the turbine flow meter at the nozzle. Data sampling bursts for 0.19 seconds continued to occur every 10 seconds throughout the entire flow range. The water flow rate was measured about every 19 LPM (5 GPM) from approximately 606 LPM (160 GPM) to 0 LPM (Fig. 13). Each flow rate was maintained for approximately 5 minutes for a minimum of 30 consecutive data sampling bursts at a single flow rate (Fig. 14). The nozzle was closed for several data bursts between each flow rate.

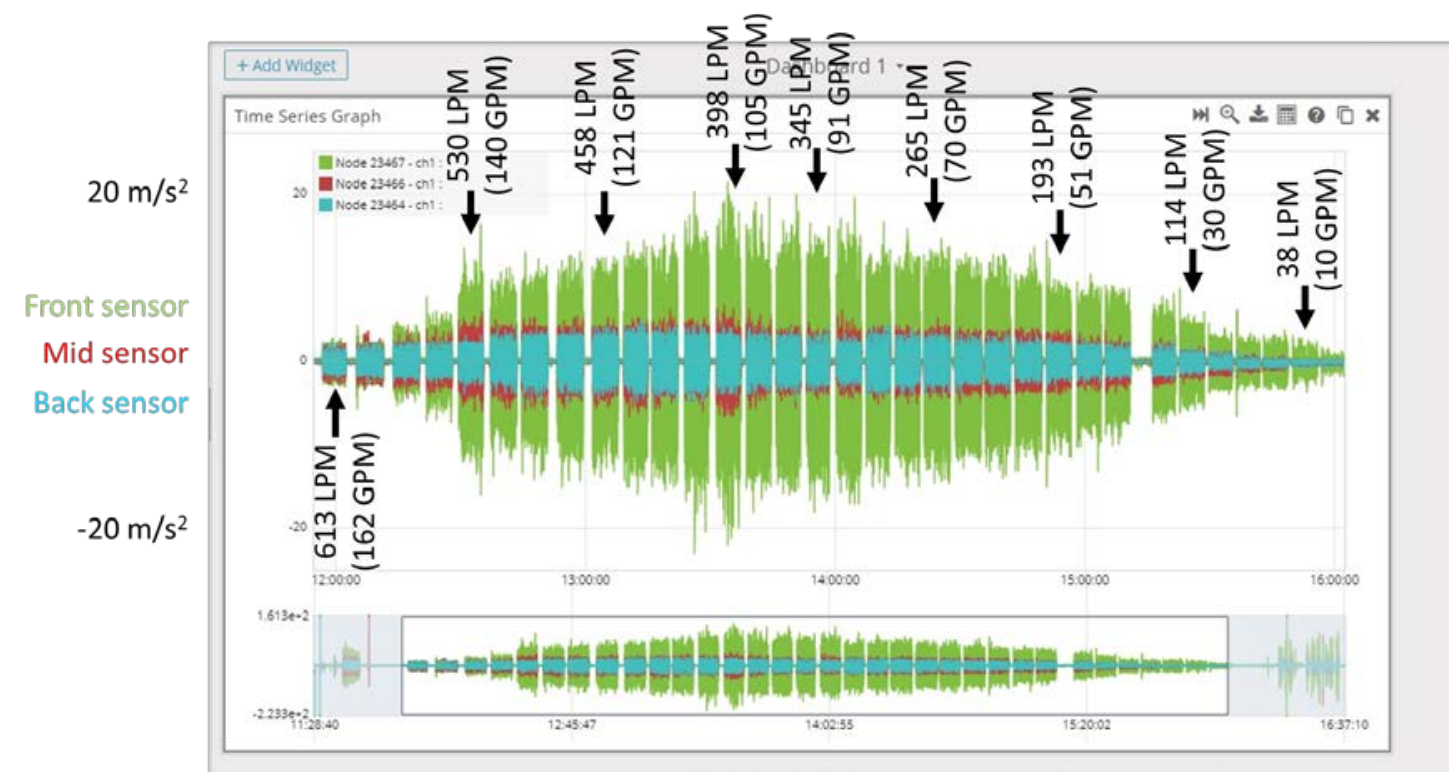

Fig. 13. Data collected (from Test 6 ) for all data sampling bursts in a time-series plot for the entire water flow range.

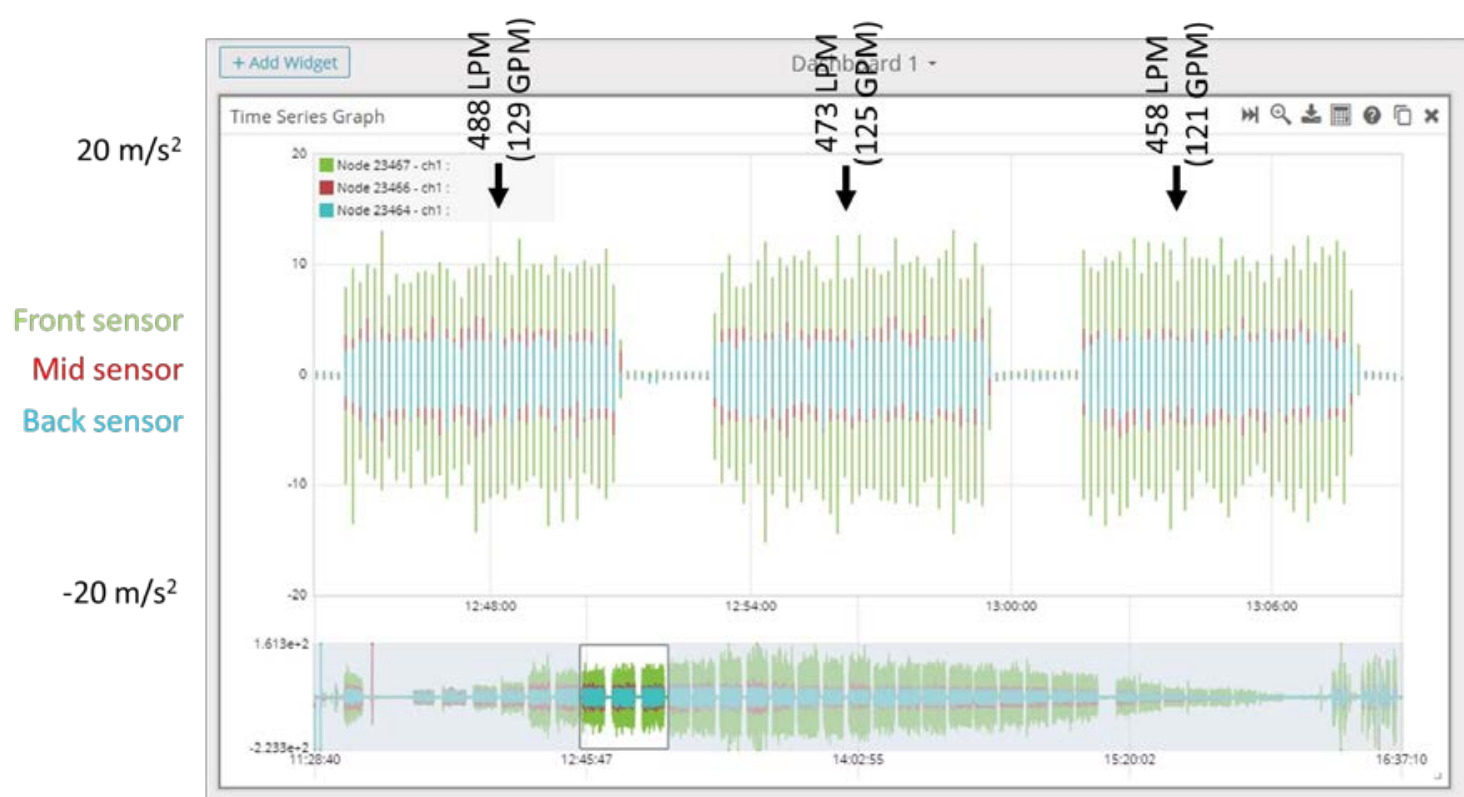

Fig. 14. Data collected (from Test 6 ) for data sampling bursts for three flow rates, 458 LPM (121 GPM), 473 LPM (125 GPM), and 488 LPM (129 GPM) in a time-series plot. 
The last ten data sampling bursts of 0.19 seconds were exported from the data collection software as .csv files. The time column within each file was originally recorded as the timeof-day and was reset to time relative to the beginning of each data burst; time was set to $0 \mathrm{~s}$ at the start of the 0.19 seconds of data, and the sampling burst ended at 0.19 seconds. Each data file was checked to confirm that each accelerometer recorded a full data set of 1900 data samples. The files were saved as text files (.txt) in preparation for data analysis.

\section{Results and Discussion - Test 4, Test 5, and Test 6}

The first step of this study was to develop the wireless sensor network to measure water flow at the fire hose nozzle using an accelerometer as the sensor. Although it was determined that the dominant frequency metric can be used to determine flow rate as documented previously, the standard deviation of acceleration was also determined at the sensor locations along the hose to compare our results to the results of the wired sensor network [23].

\subsection{Results and Discussion - Test 4, Test 5, and Test 6 - Standard Deviation of Acceleration}

The standard deviation of acceleration was determined in order to compare the results of the wireless sensor network to the wired sensor network as documented previously [23]. The raw time-series acceleration data was collected from all the accelerometers (Fig. 15). However, the standard deviation of acceleration was determined for only the Front accelerometer for each flow rate based on 1) the results of the wired testing that showed the Front accelerometer had the highest values, and 2) it was the sensor closest to the hose nozzle and therefore of most interest for our application.

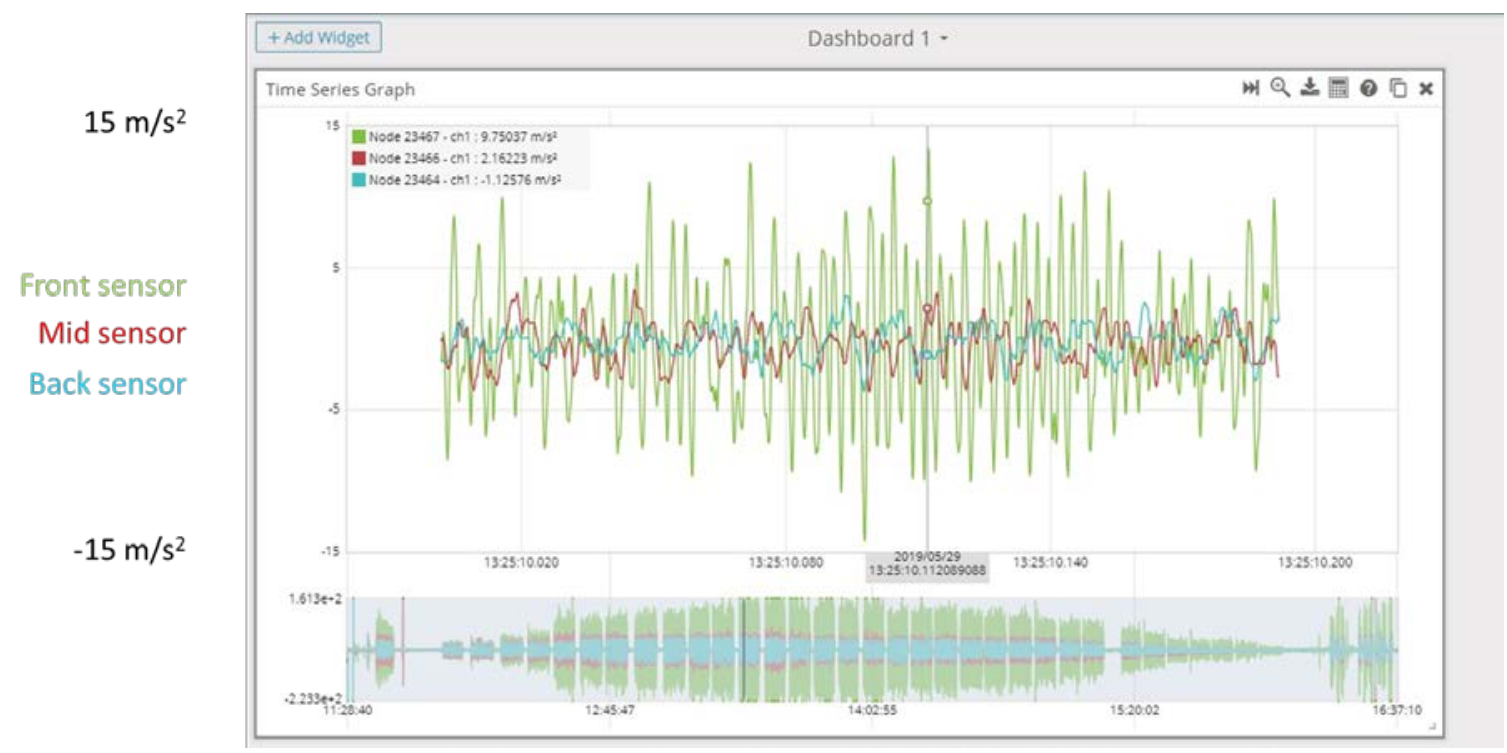

Fig. 15. Data collected (from Test 6) for a single data sampling burst for 0.19 seconds for the three accelerometers at 420 LPM (111 GPM) in a time-series plot from which the standard deviation of the signal was determined. 
The standard deviation of acceleration was determined for each flow rate for the Front accelerometer for Test 4, Test 5, and Test 6 (Fig. 16-17). Although the last 10 sampling bursts were processed at each flow rate, the data were similar such that only one sampling burst was used at each flow rate to determine the standard deviation of acceleration. The trend followed the wired sensor network tests (Test 3 shown) with a bell-shaped relationship for the flow range (Fig. 18) [23]. The decreasing trend at higher flow rates was not expected based on previous research for rigid pipes [8-10,14-16]. The peaks also continued to occur in approximately the same region as for the wired tests. Based on the bell-shaped relationship, this metric will continue to be excluded as the primary metric for determining flow rate.

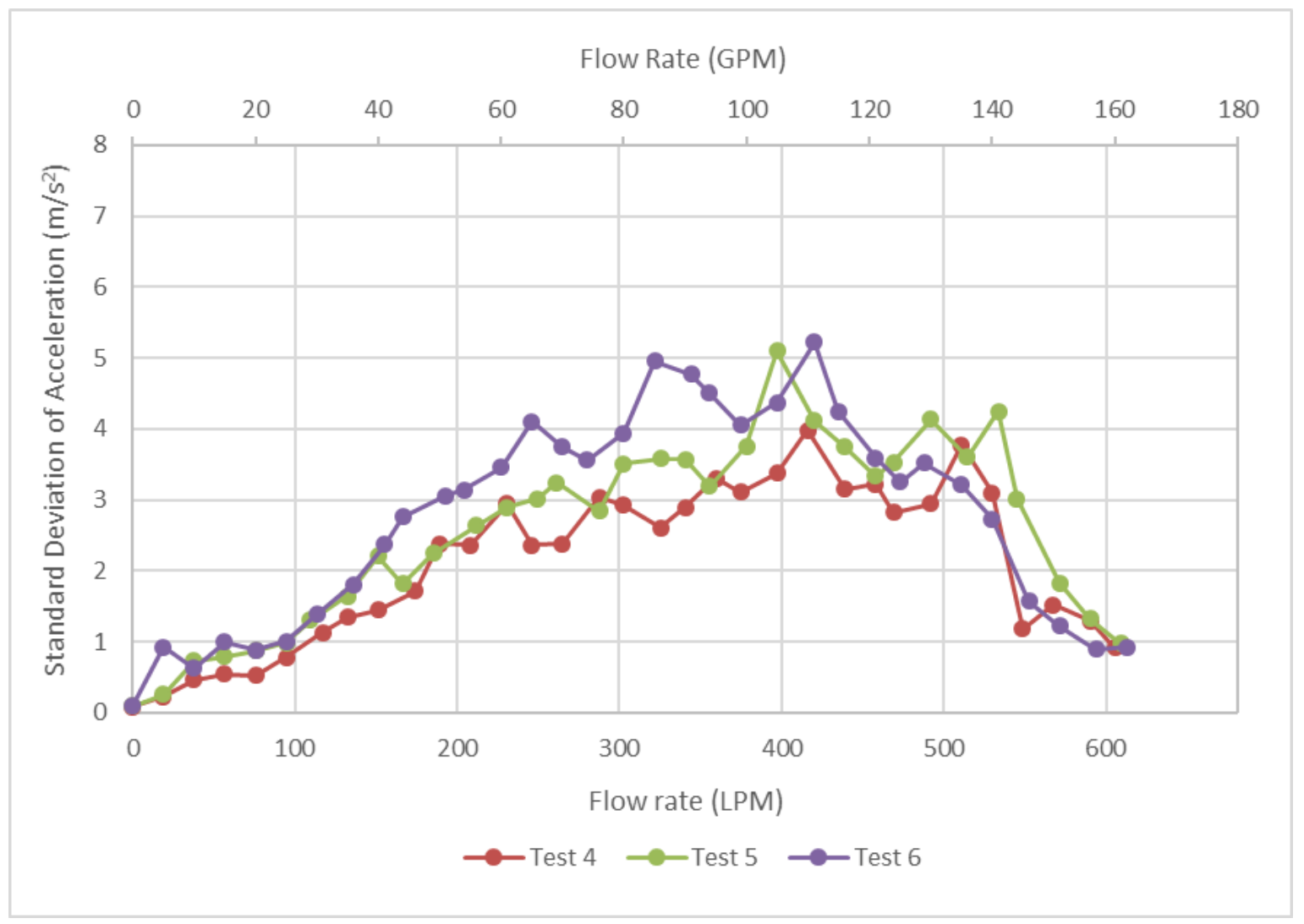

Fig. 16. The standard deviation of acceleration versus flow rate for Test 4, Test 5 , and Test 6 for the Front accelerometer. 


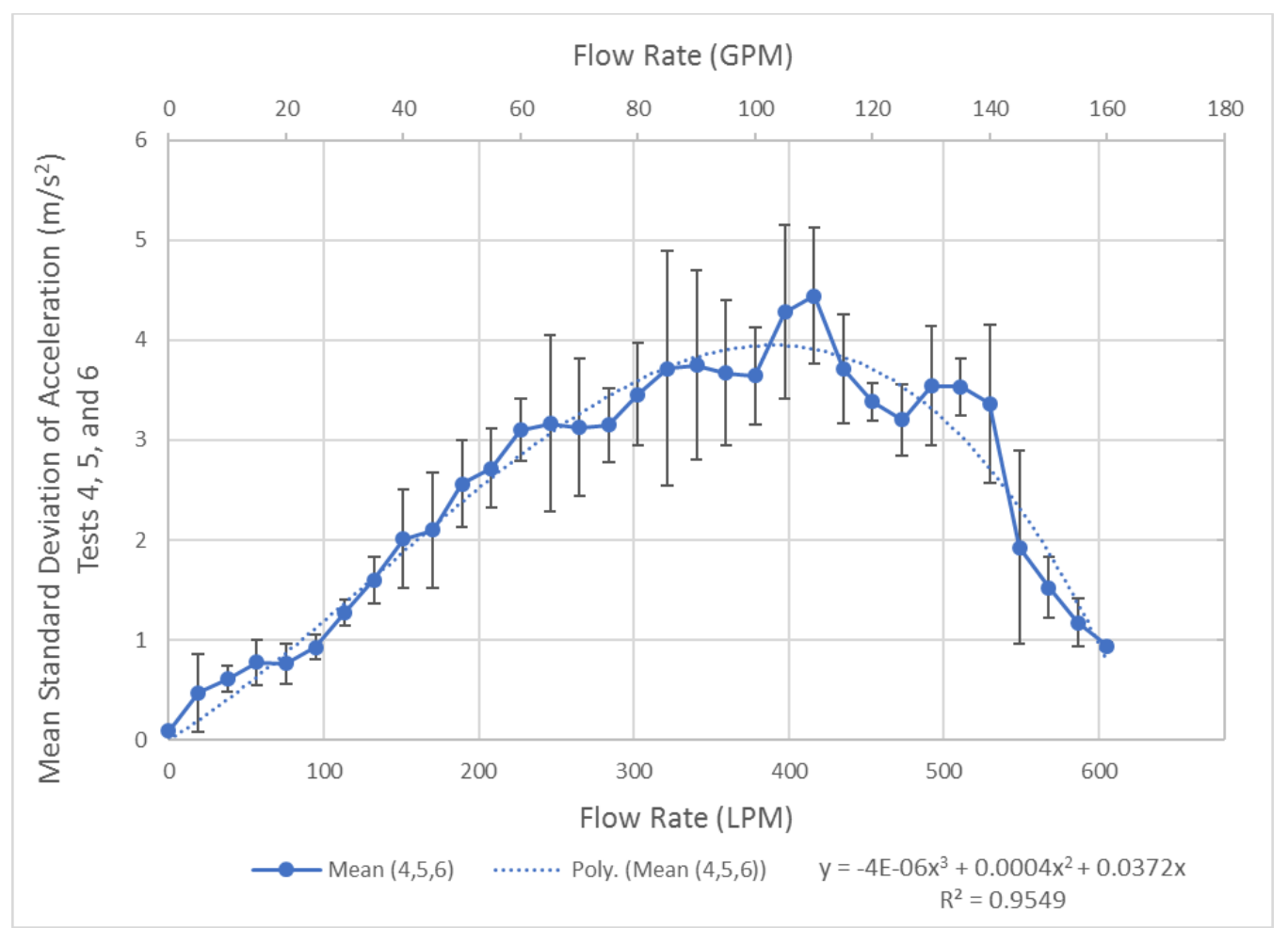

Fig. 17. The mean standard deviation of acceleration with standard deviation bars versus flow rate for the Front accelerometer from Test 4, Test 5, and Test 6.

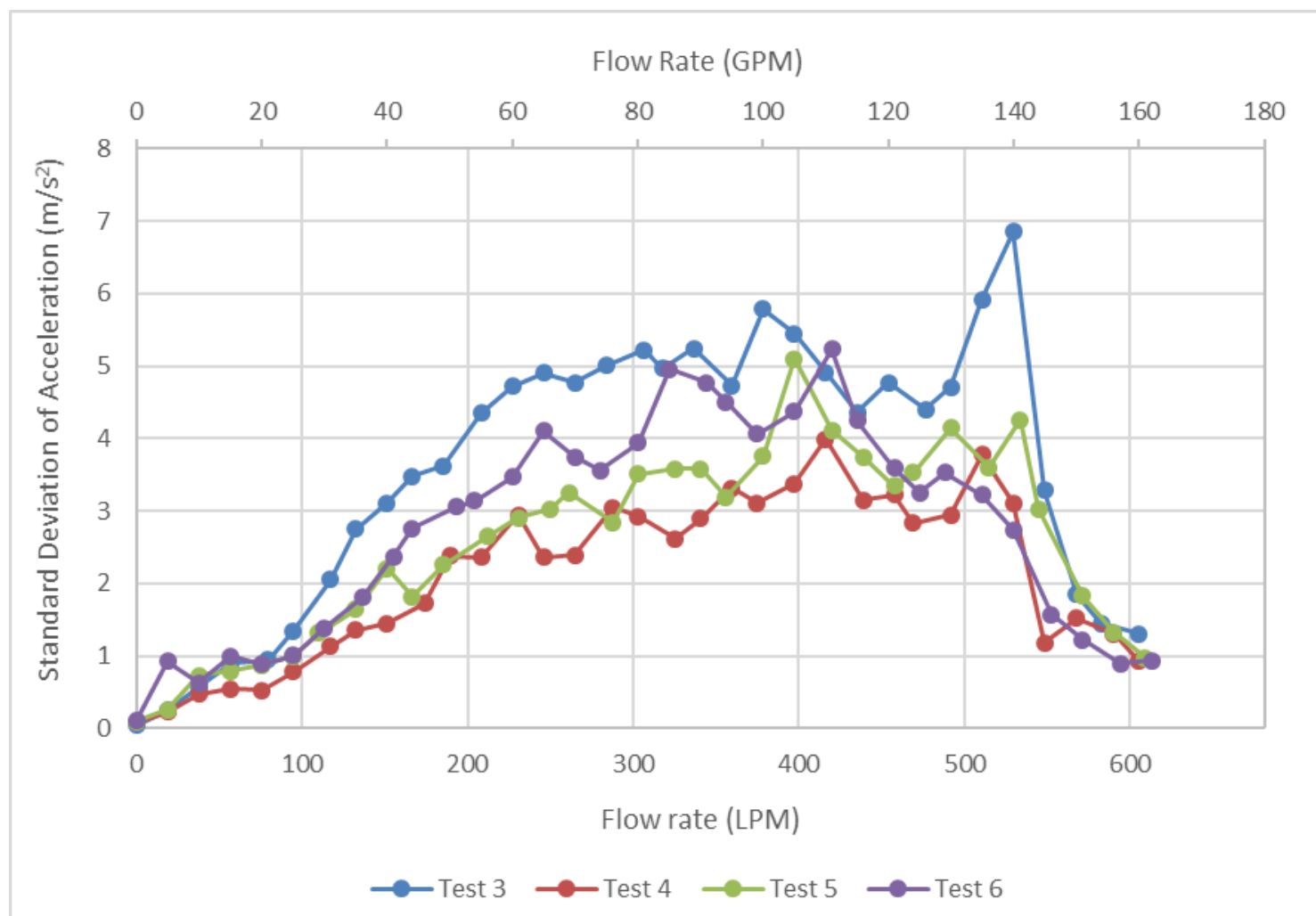

Fig. 18. The standard deviation of acceleration versus flow rate for the Front accelerometer for the wireless Test 4, Test 5, and Test 6 and wired Test 3. 


\subsection{Results and Discussion - Test 4, Test 5, and Test 6 - Initial Dominant Frequency}

Based on the previous study using the wired accelerometers, the primary metric of interest to determine flow rate was the dominant frequency of the hose [23]. The time-series accelerometer data was converted to the frequency-domain using a Fast Fourier Transform (FFT). A dominant frequency at each flow rate was determined based on the peak frequency from the power spectrum (Fig. 19).

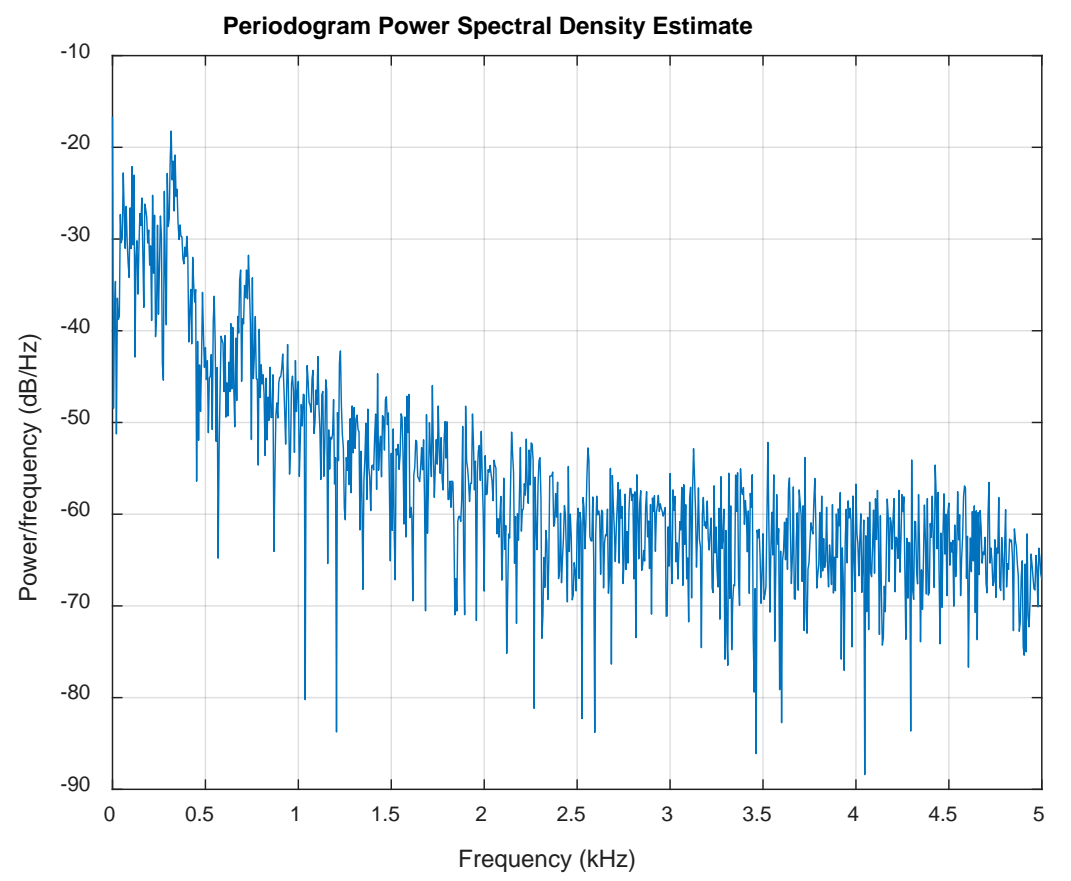

Fig. 19. A sample of the dominant frequency based on the power spectrum. A peak can be seen around $300 \mathrm{~Hz}$.

A dominant frequency at each flow rate was observed for the Front accelerometer for Test 4, Test 5, and Test 6 (Fig. 20). The dominant frequency generally decreases with increasing flow rate for water flowing within the fire hose. The dominant frequency decreases with increasing flow rate for rigid pipes $[6,11,25]$, and for flexible fire hose using a wired sensor network [23].

The dominant frequency results from Test 4, Test 5, and Test 6 for the wireless sensor network compare well to Test 3 results from the wired sensor network (Fig. 21). The same decreasing trend of the dominant frequency is observed over the flow rate range. The mean relationship for the dominant frequency and flow rate for wired Test 3 , and wireless Test 4 , Test 5 , and Test 6 , were used initially for real-time processing to determine flow rate (Fig. 22). The spread of the data was likely the result of the short data sampling burst time, which was only 0.19 seconds for the wireless Test 4 , Test 5 , and Test 6 . 


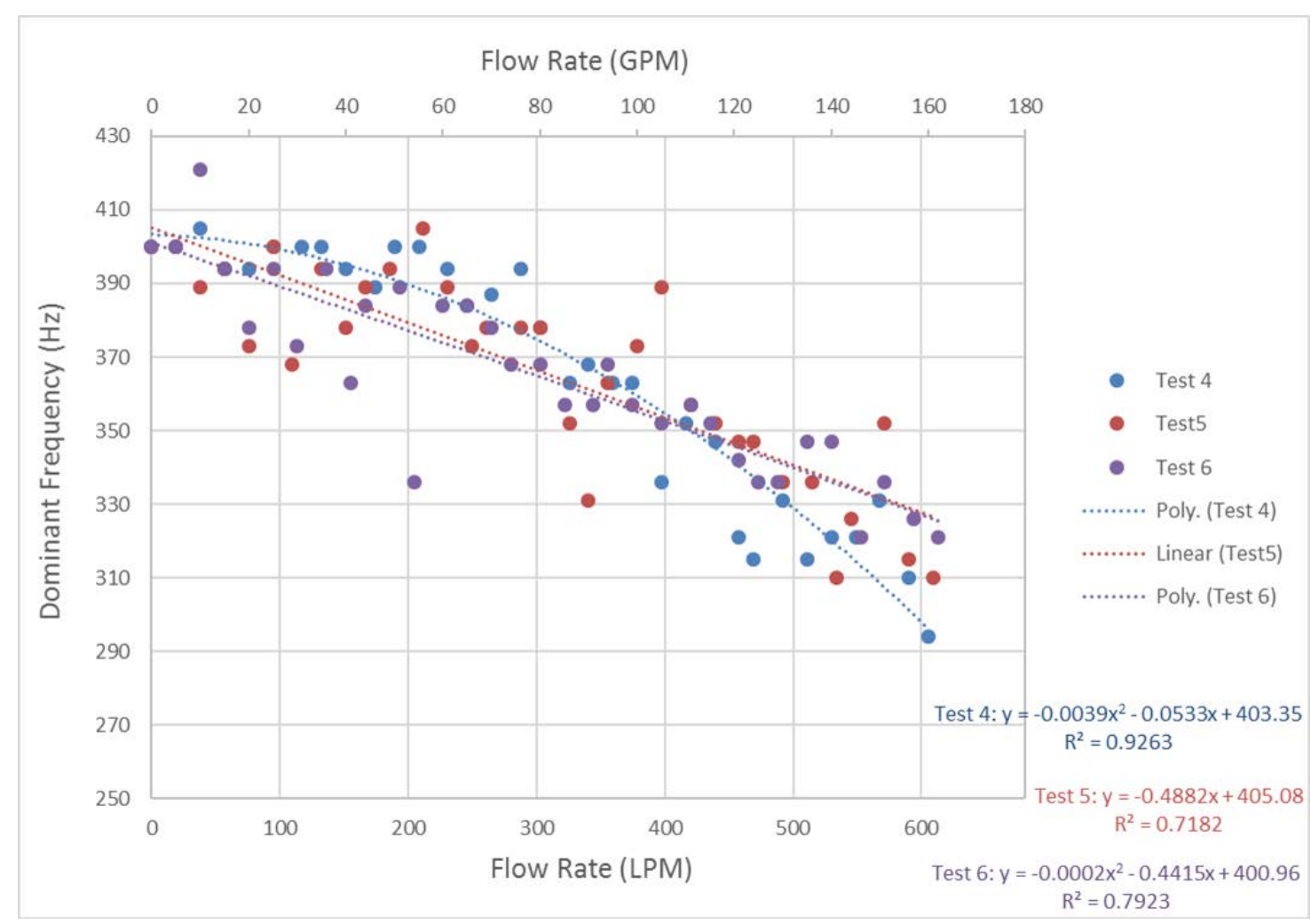

Fig. 20. Dominant frequency versus flow rate for the Front accelerometer for the wireless Test 4, Test 5, and Test 6.

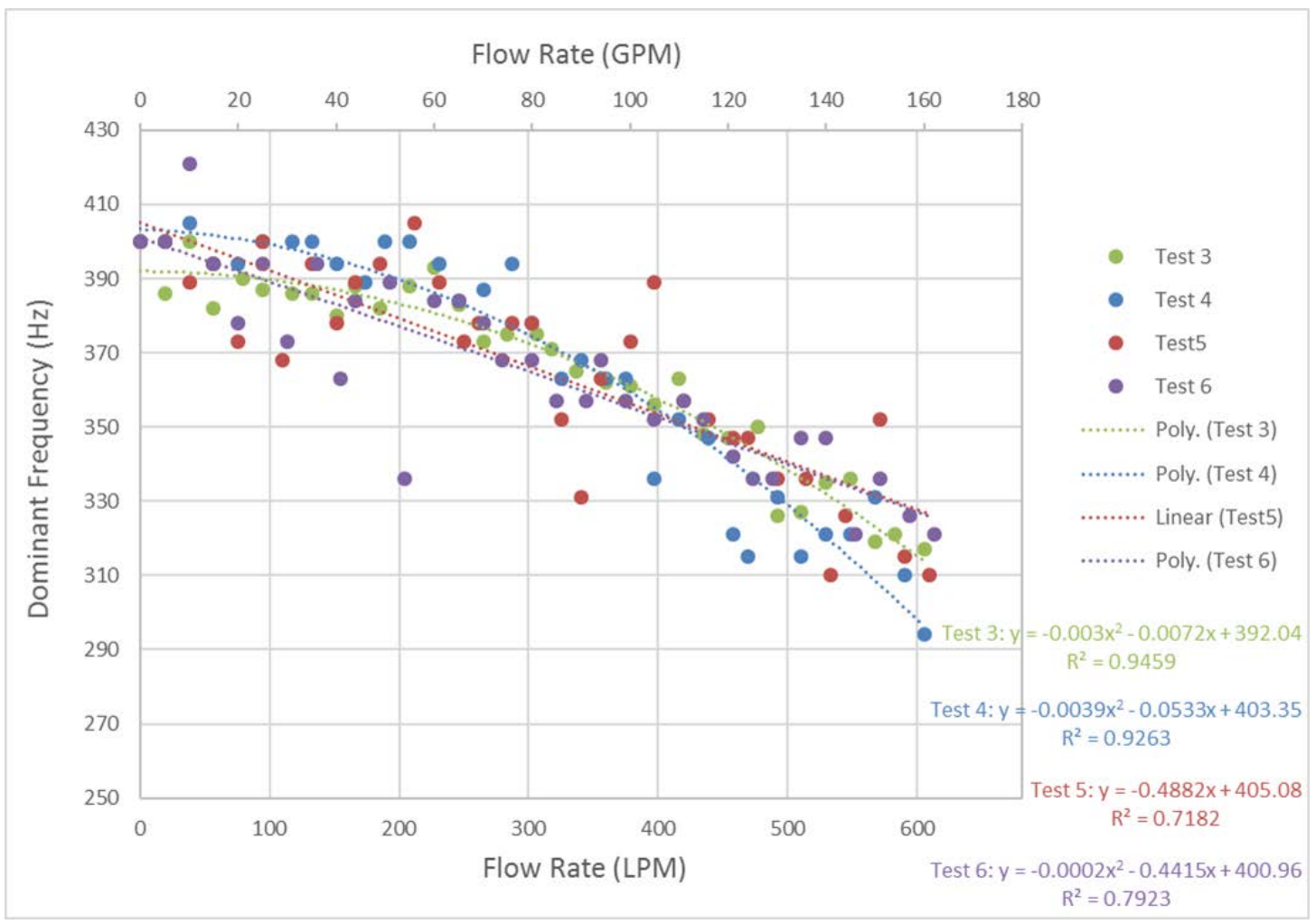

Fig. 21. Dominant frequency versus flow rate for the Front accelerometer for the wireless Test 4, Test 5, and Test 6 and for the wired Test 3. 


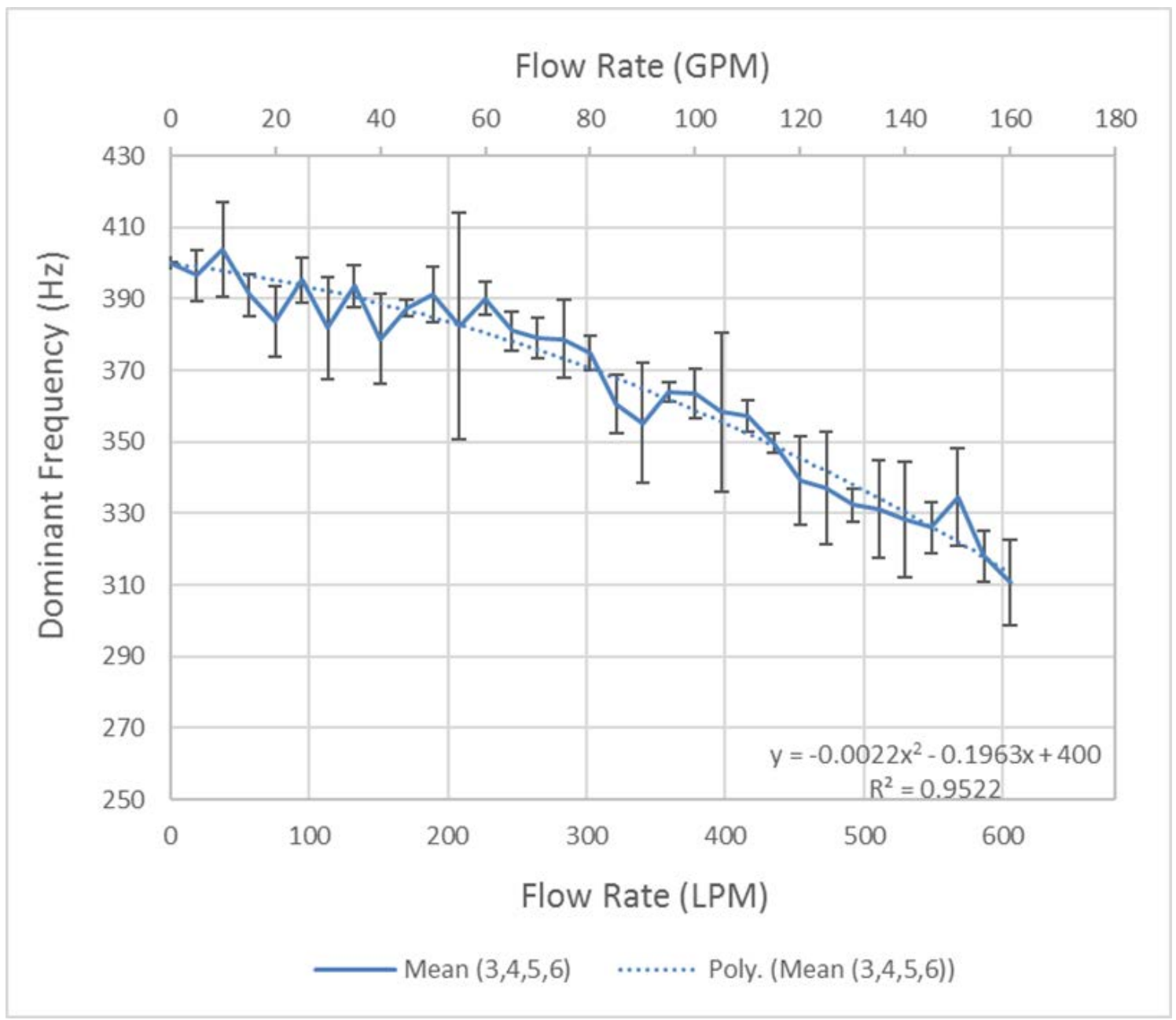

Fig. 22. The mean dominant frequency with standard deviation bars versus flow rate from wired Test 3 and wireless Test 4, Test 5, and Test 6.

The initial dominant frequency results from the Front accelerometer for the wireless sensor network, although similar to the wired tests documented previously, resulted in large values of standard deviation (Fig. 22). The scatter in the data is primarily the result of the wireless sensor network tests (Test 4, Test 5, and Test 6). Determining the flow rate was difficult from Figure 22 because of the data scatter. For example, if a dominant frequency of $340 \mathrm{~Hz}$ was detected, it could indicate a flow rate of anywhere between 337 LPM (90 GPM) and 568 LPM (150 GPM). This is a large flow range for a single dominant frequency, and for this example, could mean the difference between hose flow that is adequate with 568 LPM (150 GPM) versus inadequate flow at 337 LPM (90 GPM) for extinguishing a fire. Although Figure 22 provided an initial relationship between dominant frequency and flow rate, more testing was needed to reduce the data scatter to make real-time processing a possibility. 


\subsection{Results and Discussion - Beyond Test 4, Test 5, and Test 6 - Dominant Frequency}

The initial data sampling parameters were modified in order to capture more data to reduce the dominant frequency data scatter. The data sampling rate was lowered from $10 \mathrm{kHz}$ to $1 \mathrm{kHz}$, but the data sampling burst time was increased from $0.19 \mathrm{~s}$ to $10 \mathrm{~s}$. This change resulted in approximately five times more data being processed during the burst cycle over a longer time period of $10 \mathrm{~s}$. The raw accelerometer time-series data from the Front accelerometer was collected and processed in the custom data acquisition program. The software converted the time-series data to the frequency domain in real-time. A SavitzkyGolay filter [28] was used to smooth the frequency domain data in which the dominant frequency was identified for each flow rate (Fig. 23).

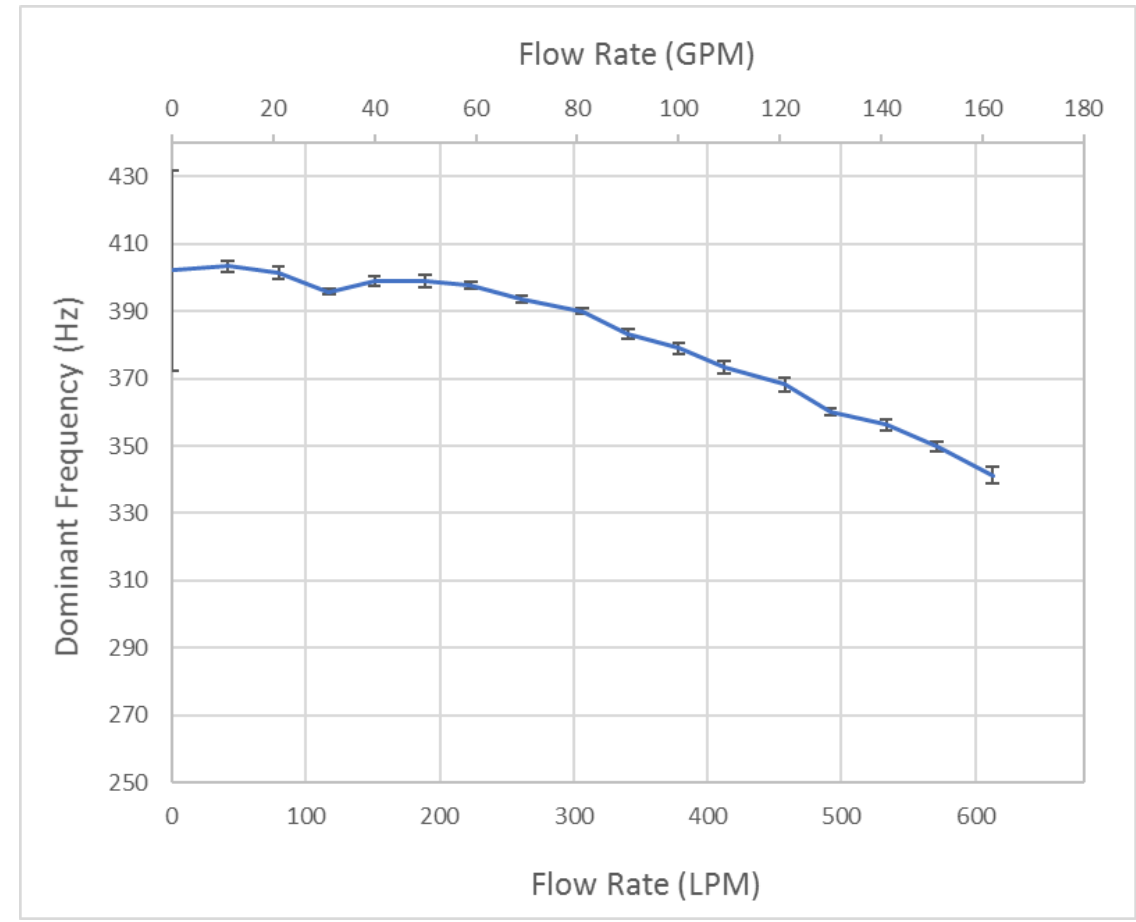

Fig. 23. Dominant frequency with standard deviation bars versus flow rate data after modifying the data sampling parameters resulting in reduced scatter, except at zero flow where the signal noise dominated causing scatter.

The use of filtering techniques resulted in reduced data scatter and standard deviation for the dominant frequency at each flow rate. The dominant frequency fluctuated less in Figure 23 than in Figure 22 with changing flow rate; the negative slope is less. However, the standard deviation bars are much smaller. The standard deviation bar at zero flow is large because the signal noise instead of the flow in the hose dominated the signal at zero flow. Other limits, discussed later, were used within the software to identify the zero-flow condition since the dominant frequency was inconsistent due to signal noise. Figure 23 was used to determine the flow rate in real-time based on the dominant frequency of the water flowing through the hose during subsequent flow tests. 


\section{Real-Time Fire Hose Flow Rate}

Data processing software was used to receive the raw time-series accelerometer data and convert the time-series to frequency-series using an FFT. The dominant frequency was then determined by the processing software to identify the flow rate using Figure 23. The graphical user interface (GUI) for the software, as seen in Figure 24, was designed as two dashboards: the 'Flow' dashboard and the 'Frequency' dashboard. The Flow dashboard displayed a colored flow bar meter to indicate the flow rate in GPM, as well as a two-light indicator for quick reference by an IC during a fire. The Frequency dashboard displayed the initial conditions for the wireless node including the dominant frequency.
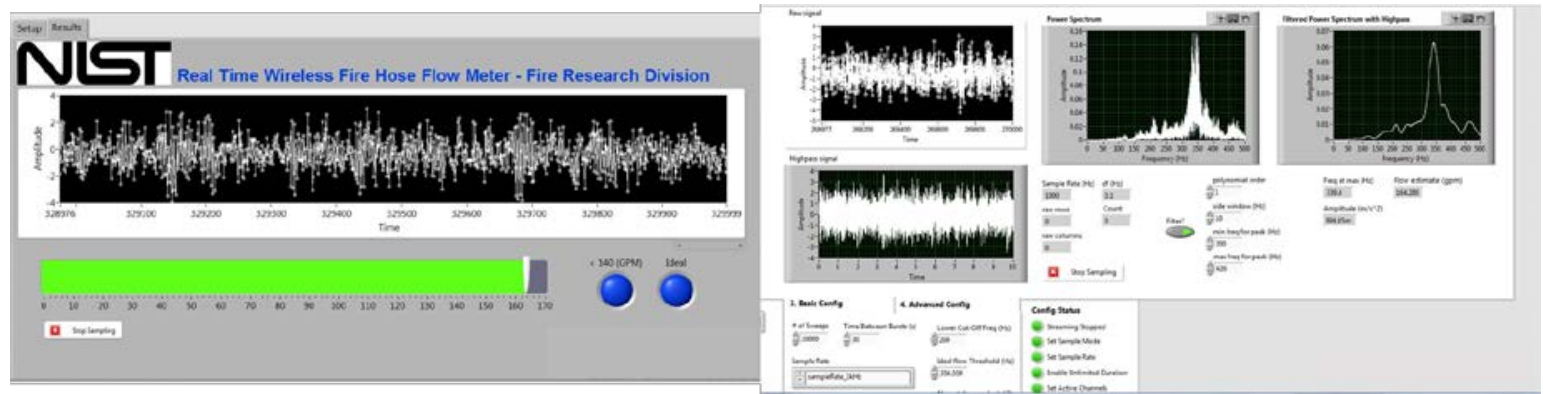

Fig. 24. The GUI - Flow dashboard (left) and Frequency dashboard (right).

The Frequency dashboard (Fig. 25) was separated into several sections. First, there was a section that displayed the basic data collection parameters such as the number of samples recorded during a data burst (i.e., 10,000 samples), sample rate (1 kHz) and time between bursts (30 s). Second, a time-series plot displayed the raw acceleration signal including amplitude. Third, the raw power spectrum signal showed the dominant frequency along with the Savitzky-Golay smoothing filter input data. Fourth, the filtered power spectrum showed the dominant frequency after the smoothing filter. Fifth, the value of the dominant frequency based on the filtered power spectrum, and the amplitude of the time-series accelerometer data were shown. Sixth, the flow rate estimate (in GPM) was displayed based on the dominant frequency in Figure 23. 


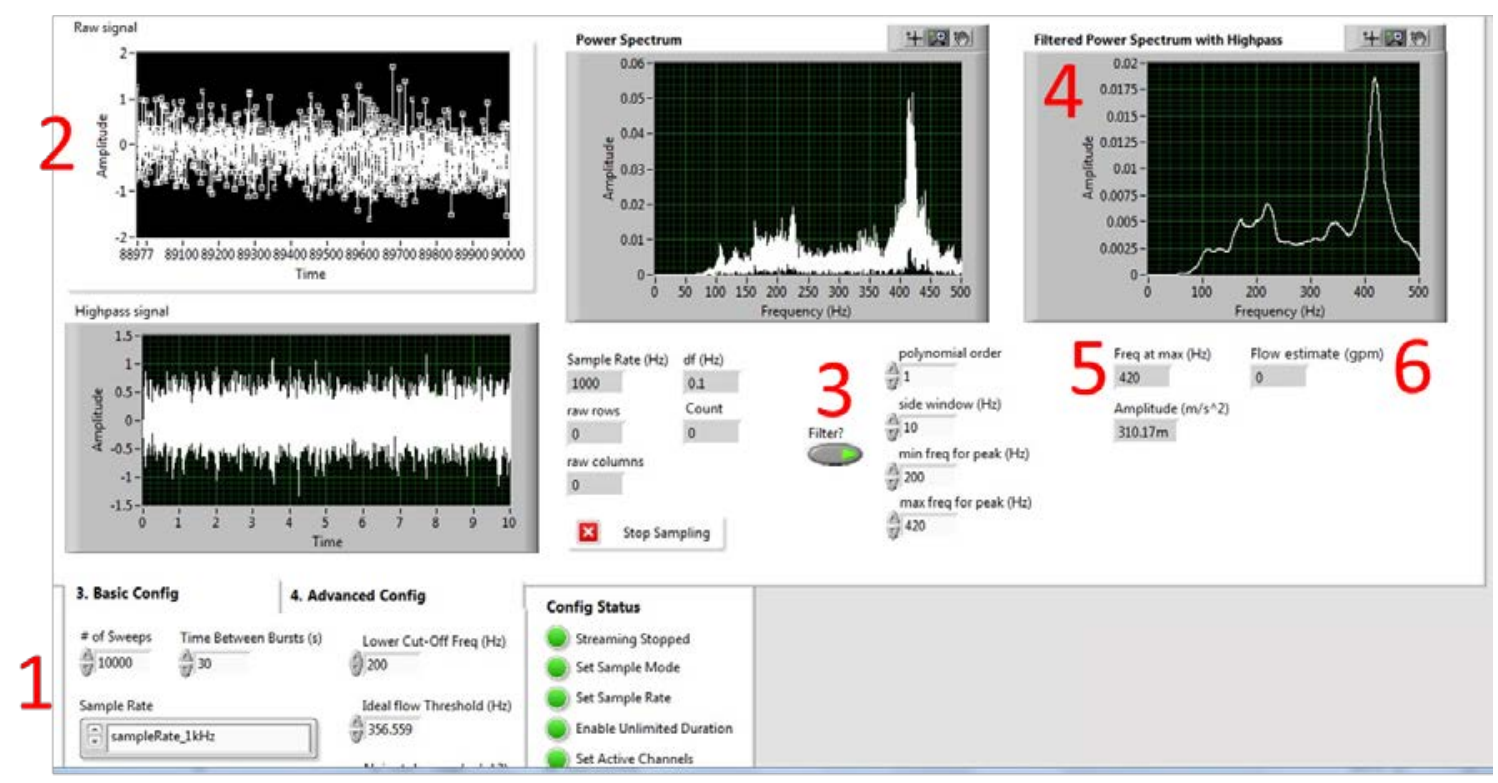

Fig. 25. The Frequency dashboard for the zero-flow condition: 1) the initial settings, 2) the raw time-series signal, 3) filtering input, 4) filtered frequency, 5) dominant frequency, 6) flow rate based on the dominant frequency.

Figure 25 shows the Frequency dashboard during the zero-flow condition. During zero-flow, the software also monitored the amplitude of the time-series signal. If the amplitude of the time-series signal was less than $0.5 \mathrm{~m} / \mathrm{s}^{2}$ then the no-flow condition would remain regardless of the dominant frequency. The amplitude of the noise during the no-flow condition did not typically exceed approximately $0.5 \mathrm{~m} / \mathrm{s}^{2}$ but the dominant frequency of the noise could jump into a dominant frequency range as shown in Figure 23 with the large data scatter at zero flow. To avoid the signal noise triggering a false dominant frequency measurement, the amplitude must exceed a minimum value of $0.5 \mathrm{~m} / \mathrm{s}^{2}$. In the raw power spectrum plot, there was a lot of signal at the lower frequencies, between 150 and $250 \mathrm{~Hz}$. Filtering removed that signal below $200 \mathrm{~Hz}$ so that the dominant frequency was not influenced by the noisy lower frequency signals.

In the Flow dashboard, there were three main sections (Fig. 26). First, the time-series plot of the raw acceleration signal was shown. Second, a colored bar meter displayed the flow rate both numerically and visually. The bar was red when the flow rate was less than 50 GPM (dominant frequency between $399 \mathrm{~Hz}$ and $403 \mathrm{~Hz}$ ), yellow between $50 \mathrm{GPM}$ and $140 \mathrm{GPM}$ (dominant frequency between $399 \mathrm{~Hz}$ and $356 \mathrm{~Hz}$ ) and green when the flow rate was 140 GPM or above (dominant frequency $356 \mathrm{~Hz}$ or less). Third, there was a two-light indicator that showed no lights for the no-flow condition, one blue light when flow was measured up to 140 GPM, and then two lights were illuminated when the flow exceeded 140 GPM. The two-light display was for a quick reference for an IC to easily check on the flow rate. Figure 26 shows the Flow dashboard for the zero-flow condition; signal amplitude less than $0.5 \mathrm{~m} / \mathrm{s}^{2}$, bar meter showed red at $0 \mathrm{GPM}$, and neither blue lights were illuminated. 


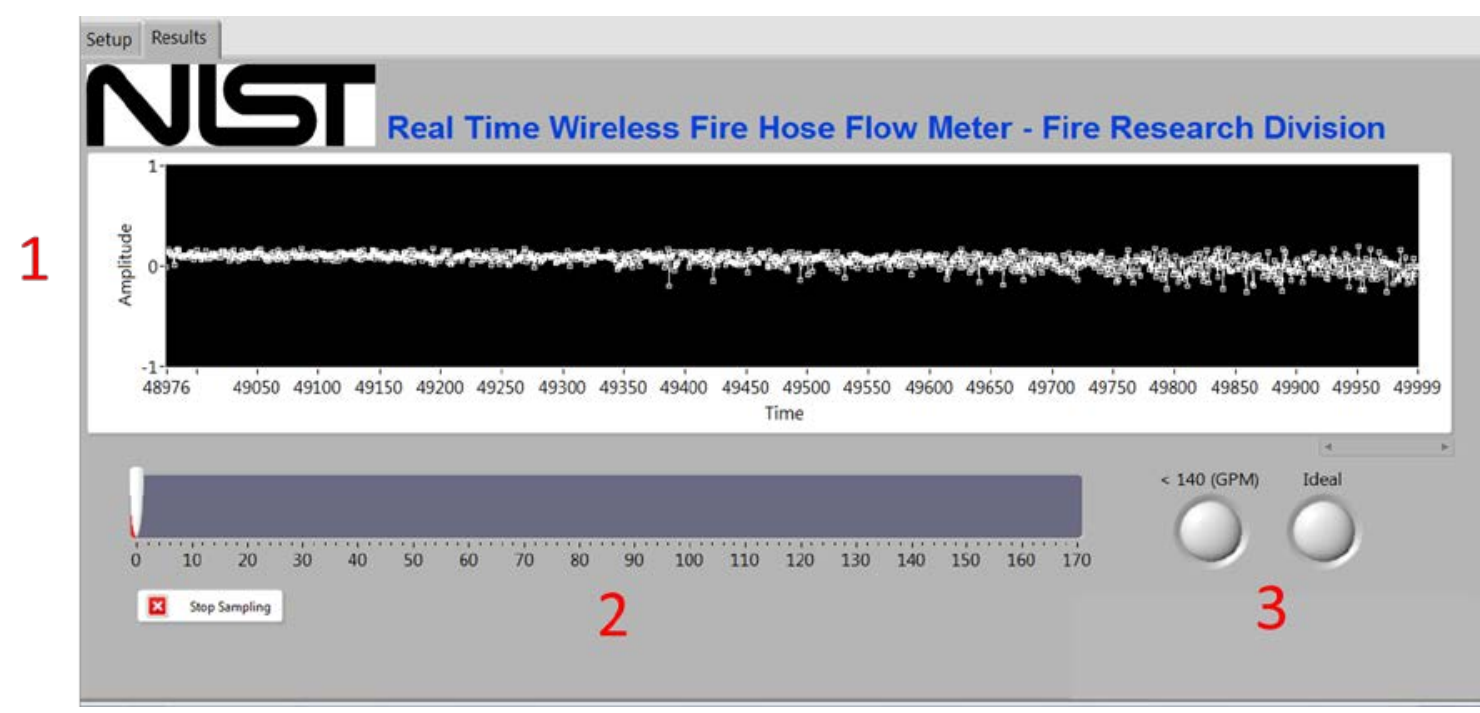

Fig. 26. The Flow dashboard for no-flow: 1) the time-series signal, 2) a bar meter for the flow rate of 0 GPM, 3) two-light indicator for flow rate.

At 100 GPM, the Frequency dashboard displayed a higher raw time-series signal amplitude up to approximately $10 \mathrm{~m} / \mathrm{s}^{2}$ (Fig. 27). This amplitude corresponded with Figure 17 that showed the peak standard deviation of acceleration occurring often around approximately 100 GPM. The dominant frequency was shown on the dashboard as $378.6 \mathrm{~Hz}$ which corresponded to approximately 100 GPM as shown in Figure 23.

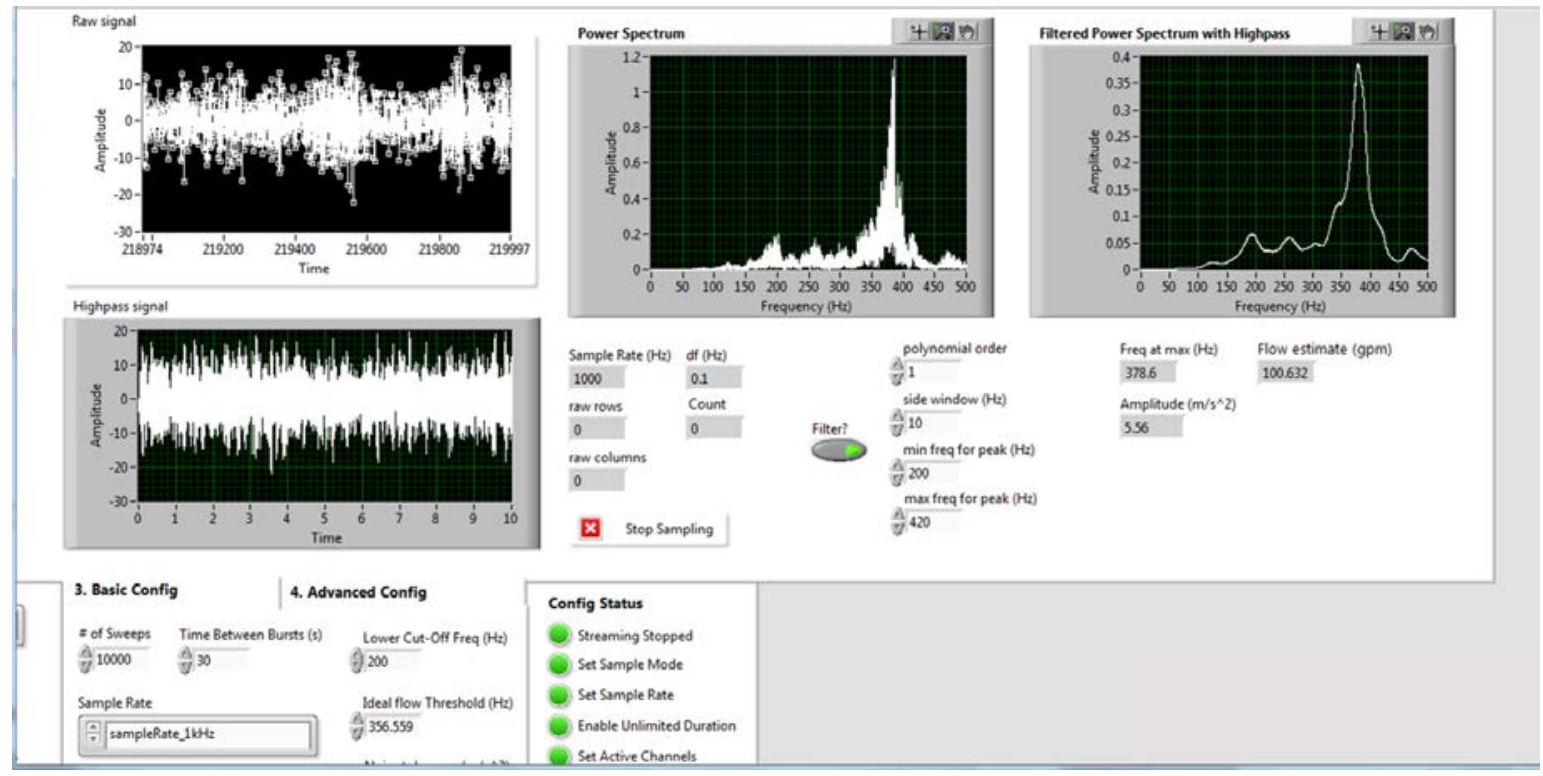

Fig. 27. The Frequency dashboard for 100 GPM and displayed a dominant frequency of $378.6 \mathrm{~Hz}$. 
On the Flow dashboard, the bar meter showed yellow for the 100 GPM flow rate, and one of the two blue lights was illuminated indicating flow. Although flow was indicated (thus the yellow color, and one light illuminated), the flow rate was less than the goal of 150 GPM [29] for a fire hose attacking a single-family dwelling fire (Fig. 28).

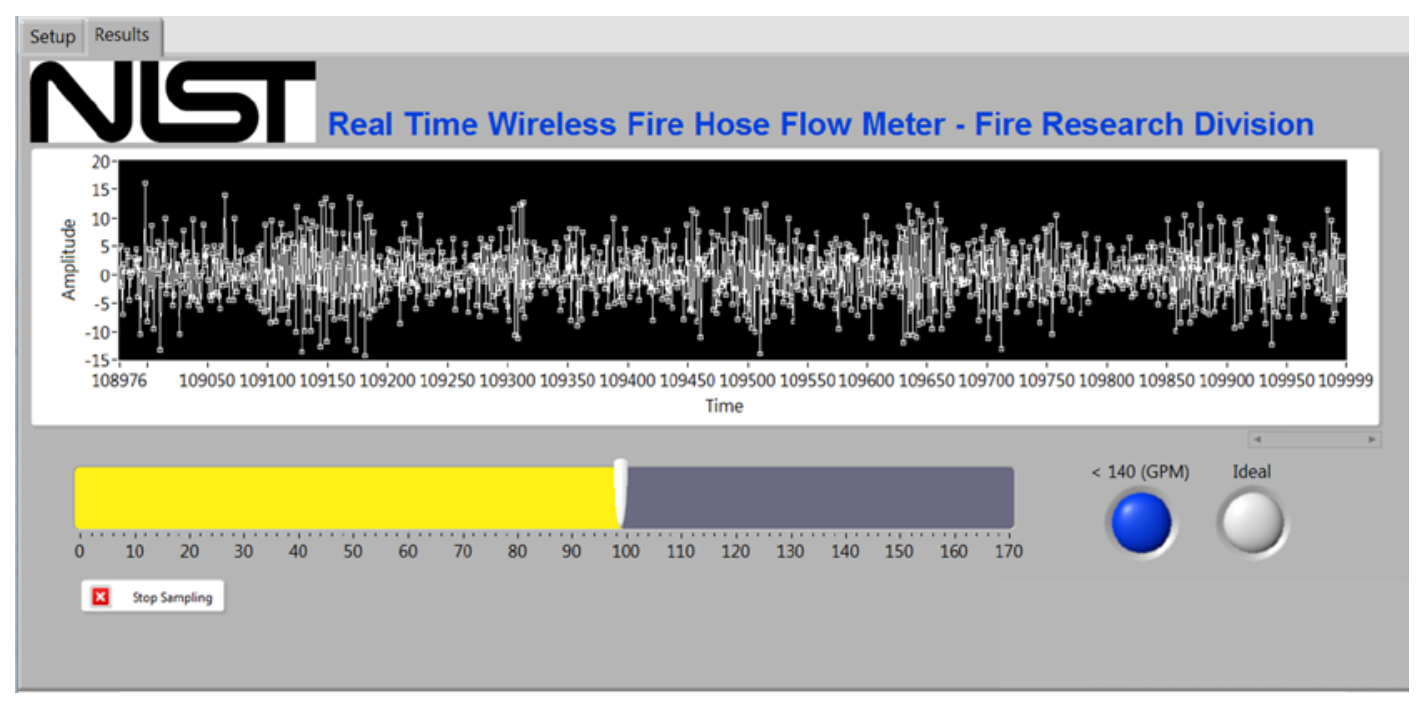

Fig. 28. The Flow dashboard for 100 GPM with yellow colored bar meter and with one blue light illuminated.

At 164 GPM, the Frequency dashboard displayed a smaller amplitude on the raw time-series plot (Fig. 29). This corresponded to the trend in the standard deviation of acceleration results (Fig. 17) where a decrease in standard deviation occurred at higher flow rates. On the raw power spectrum, two peaks were seen to be competing for dominance. The Savitzky-Golay smoothing filter reduced the two competing frequencies to one dominant frequency value.

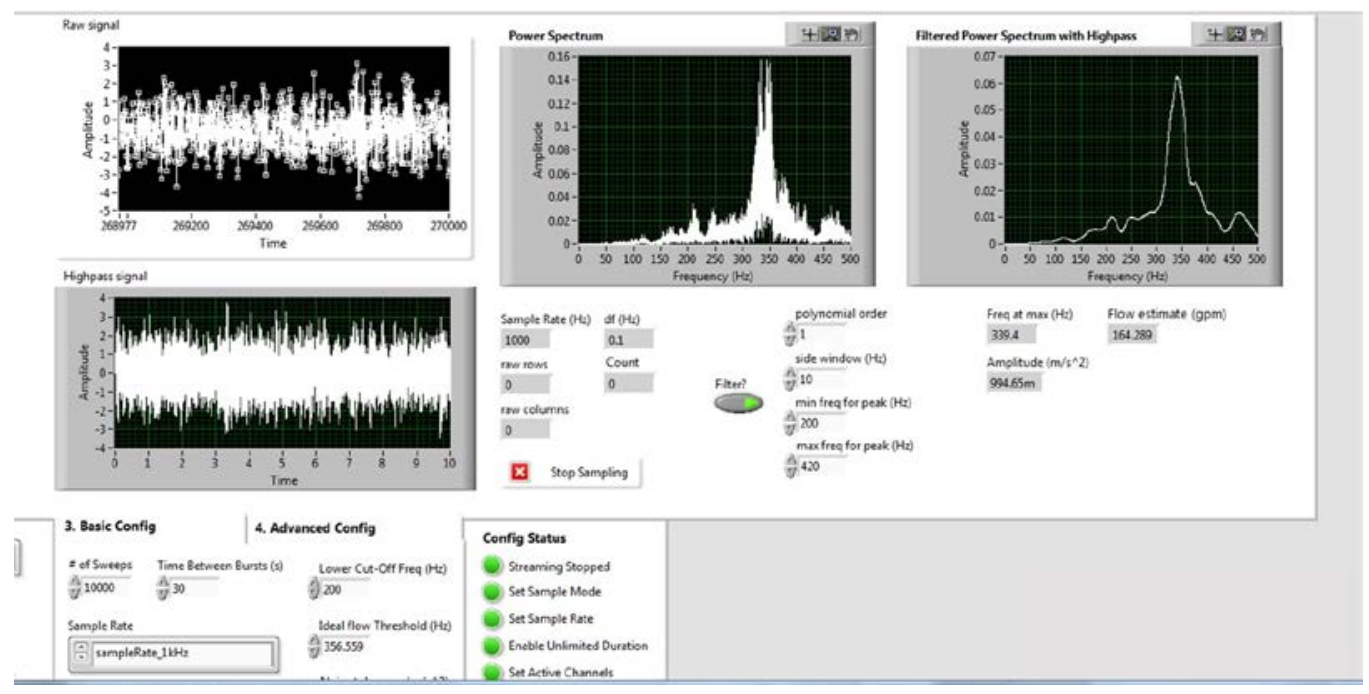

Fig. 29. The Frequency dashboard for 164 GPM. Note the Savitzky-Golay smoothing filter reduced the two peaks seen in the raw power spectrum to one dominant frequency. 
On the Flow dashboard, the bar meter for flow rate was green since the flow rate was above 140 GPM (Fig. 30). Both blue lights were illuminated on the 2-light indicator since the flow rate was above $140 \mathrm{GPM}$. The IC can refer to the two blue lights and know that the attack hose has a flow rate above 140 GPM at the nozzle.

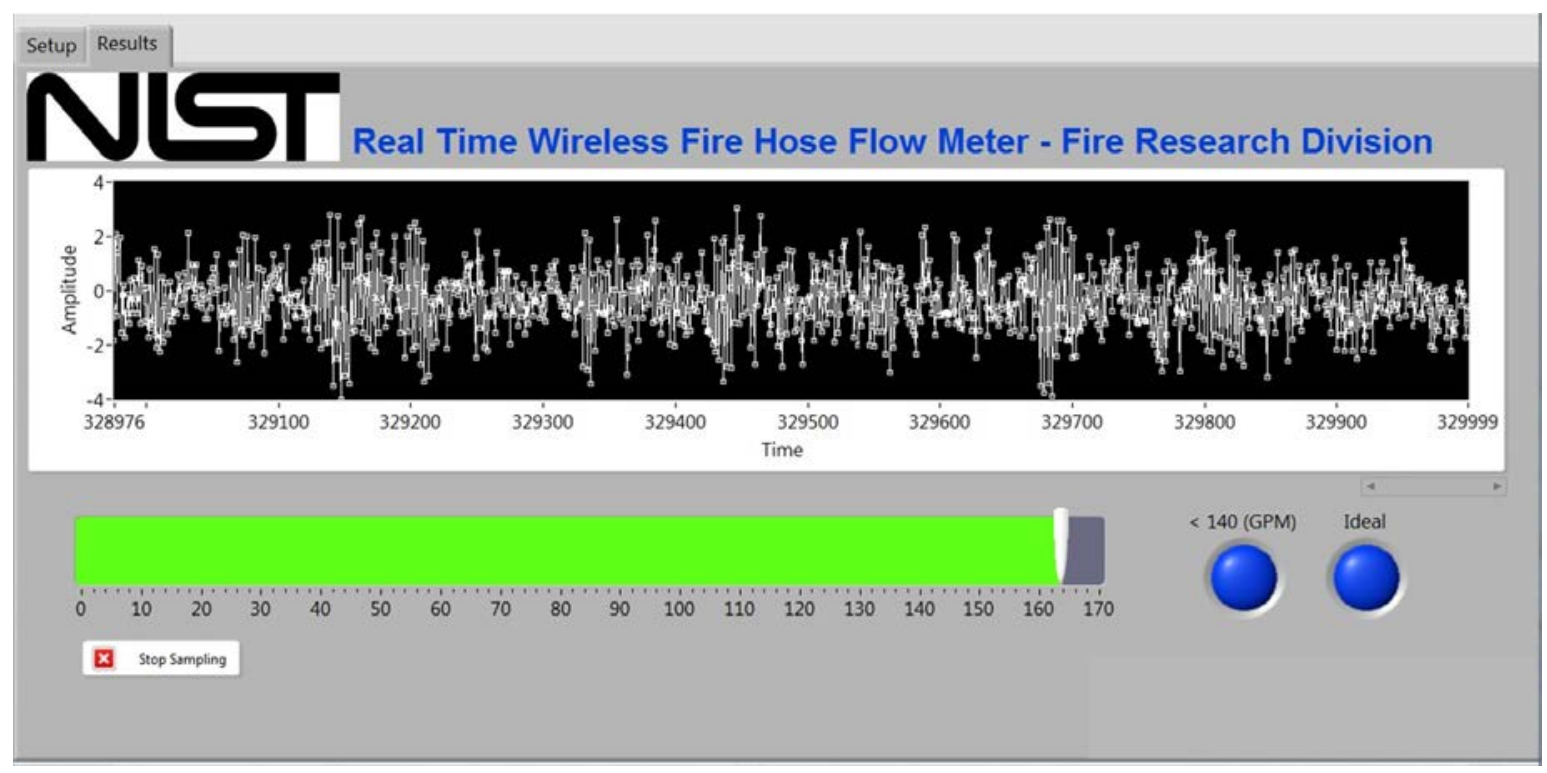

Fig. 30. The Flow Panel for 164 GPM with green colored meter and with two blue lights illuminated.

\section{Practical Considerations for a Nozzle Flow Meter}

There were several limitations to the wireless sensor network that need to be resolved before applying this wireless sensor network to a fire hose.

1. Power - The sensor, wireless nodes, and base station required power. In this study, power was supplied to the accelerometers from the nodes, and from the laptop to the base station. For the fire hose application, the wireless nodes and sensor will need a source of power. Replaceable or rechargeable batteries may work.

2. Hostile environment - The wireless sensor network in this study was applied to the fire hose in a non-hostile, outside, environment. The wireless sensor network on a fire hose on the fireground will need to be capable of withstanding high temperature, water, and must be durable to survive being dragged on the ground while attached to the exterior fabric of the fire hose. The protective case used in this study was intended to provide only minimum protection during testing.

3. Equipment size - In this study, the accelerometer and the wireless node were separate, and the node was too large to be applied directly to a fire hose. Combining the accelerometer and the wireless node together and reducing the node size would be required for adoption 
to an actual fire hose. Although already sufficiently lightweight, a smaller single unit containing both the sensor and node with a lower profile would be less likely to be damaged during use on the fireground.

4. Signal strength and range - The wireless node in this study used radio frequency (RF) signals to transmit data to the base station. In order to maximize the signal range, physical barriers should be minimized, radio frequency interference and electromagnetic interference should be minimized, and metal near the node or base station antenna should be minimized [27, 30]. For an actual fire hose application, the node will not likely have a clear line of sight to the base station, either due to structural obstructions like interior and exterior walls, floors, ceilings, or doors. Ground terrain may prevent a clear line of site in a forest or if the node is underground in a basement. There may also be civilian sources of RF signals as well as radio interference from fire department sources that could interfere or weaken the RF signal from the flow meter. Preventing the loss of a signal due to these factors will be important.

5. Metric robustness - Because the dominant-frequency metric was based on acceleration at the hose surface, the dominant-frequency metric was affected by hose structural dynamics. The relationship of dominant frequency to flow rate (Fig. 23) changed slightly based on factors including (1) bending of the hose, (2) placement of the hose on stiff concrete or pliable grass foundation, (3) pressure and head loss, (4) friction inside the hose. Currently, filtering is used to eliminate lower-frequency affects from other sources, such as the pump on a fire engine. However, low-frequency movements of the hose that cause the hose dynamics to change may affect the dominant frequency, which is an undesired situation. For example, the difference in slopes and values between Figure 22 and Figure 23 was due mainly to the different hose dynamics from the differences in experimental setup. Thus, a more robust metric needs to be established to accommodate these differences in hose dynamics.

\section{Uncertainty}

There were several possible sources of uncertainty in this study, which must be considered. The commercial flowmeter specifications report a $\pm 1 \%$ accuracy over the flow range for the meter. This supports the range of drift in the flow rates from the reference flow meter, mentioned earlier in this report, of approximately \pm 3.8 LPM (1.0 GPM) at the higher reference flow rates and less drift of approximately \pm 1.9 LPM (0.5 GPM) at lower reference flow rates. The fittings upstream and downstream of the reference flow meter may have slightly altered the water flow dynamics as it passed through the turbine affecting the reference flow meter's measurement. There was also a likely contribution of uncertainty in our measurements attributed to the fluctuation in the water flow from the water source; the water utility pipes of the building supplied the water to the fire hose. The uncertainty contribution from the water supply is likely to be a much larger contribution than the uncertainty from the accelerometers. The measurement uncertainty from the accelerometers, at the $95 \%$ confidence level with coverage factor of 2 , was less than $\pm 1.0 \%$ for the frequency range used in this study. The real-time wireless flow meter output was typically within about \pm 10 GPM of the commercial flow meter throughout the flow range tested, or 
within between $6 \%$ and $16 \%$ of the commercial flow meter output. The intention of the wireless flow meter was not to provide an exact numerical flow rate to an incident commander on the fireground, but rather to give the IC a visual representation of the approximate flow rate using the 2-light-indicator. Reducing the total uncertainty of the realtime wireless flow meter output will be the focus of additional research.

\section{Conclusion}

The focus of the previous technical note [23] was the development of the wired accelerometer as a sensor to determine flow rate near the nozzle of a fire hose. The dominant frequency metric yielded a relationship with flow rate for an accelerometer located close to the hose nozzle. The focus of this technical note was 1) the development of the wired accelerometer system into a wireless sensor network, and 2) the application of the dominantfrequency metric to determine real-time water flow in a fire hose to improve fireground situational awareness. A nearly monotonic relationship of flow rate to the dominant frequency was established and then used in a custom GUI for quick, real-time, visual referencing by fire personnel of flow rate in a fire hose. While more work is needed, such as improved physical robustness of the sensor-node assembly and increase robustness of the signal metric, this preliminary study showed the potential of a "smart" fire hose for improved situational awareness during a fire attack.

\section{References}

[1] Petrillo AM (2019) Hoses: Large and Small, from LDH to Forestry Lines. Fire Apparatus and Emergency Equipment. June, 24(6). https://digital.fireapparatusmagazine.com/fireapparatus/june_2019/MobilePagedRepli ca.action?pm=2\&folio=16\#pg16

[2] Hamins A, Grant C, Bryner N, Jones A, Koepke G (2015) Research Roadmap for Smart Fire Fighting, National Institute of Standards and Technology, Gaithersburg, MD, NIST Special Publication (SP) 1191. https://doi.org/10.6028/NIST.SP.1191

[3] Clinch JM (1969) Measurements of the wall pressure field at the surface of a smoothwalled pipe containing turbulent water flow. J. Sound Vib 9(3): 398-419.

[4] Kim YK, and Kim YH (1996) A three accelerometer method for the measurement of flow rate in pipe. J. Acoustical Society of America, 100(2): 717-726.

DOI:10.1121/1.416211

[5] Park G, Cudney HH, Inman DJ (2001) Feasibility of using impedence-based damage assessment for pipeline structures. Earthquake Engng. Struct. Dyn., 30: 1463-1474.

DOI: 10.1002 eqe.72 
[6] Evans RP, Blotter JD, Stephens AG (2004) Flow rate measurements using flowinduced pipe vibration. Transactions of the ASME 126: 280-285. DOI: $10.1115 / 1.1667882$

[7] Pittard MT, Evans RP, Maynes RD, and Blotter JD (2004) Experimental and numerical investigation of turbulent flow induced pipe vibration in fully developed flow. Review of Science Instruments 75(7): 2393-2401. DOI: 10.1063/1.1763256

[8] Thompson AS, Maynes D, and Blotter JD (2010) Internal turbulent flow induced pipe vibrations with and without baffle plates, Proceedings of the ASME 2010 3rd Joint US-European Fluids Engineering Summer Meeting and 8th International Conference on Nanochannels, Microchannels, and Minichannels. Aug 1-5, Montreal, Canada.

[9] Urthaler Y, Breaux LE, McNeill SI, Luther EM, Austin J, Tognarelli M (2011) A Methodology for assessment of internal flow-induced vibration (FIV) in subsea piping systems, Proceedings of the ASME $201130^{\text {th }}$ International Conference on Ocean, Offshore and Arctic Engineering, June 19-24, Rotterdam, The Netherlands.

[10] Dinardo G, Fabbiano L, Vacca G (2013) Fluid flow rate estimation using acceleration sensors. Seventh Int. Conf. on Sensing Technology, pp. 221-5.

[11] Campagna MM, Dinardo G, Fabbiano L and Vacca G (2015) Fluid flow measurements by means of vibration monitoring. Meas. Sci. Technol. 26. DOI:10.1088/0957-0233/26/11/115306

[12] Medeiros KAR, Barbosa CRH, and Oliveira EC (2015) Flow measurement of piezoelectric accelerometers: application in the oil industry. Petroleum Science and Technology 33:1402-1409. DOI:10.1080/10916466.2015.1044613

[13] Medeiros KAR, Oliveira FLA, Barbosa CRH, and Oliveira EC (2016) Optimization of flow rate measurement using piezoelectric accelerometers: application in water industry. Measurement 91:576-581.

[14] Yazdekhasti S, Piratla KR, Atamturktur S, Khan AA (2016) Novel vibration-based technique for detecting water pipeline leakage. Structure and Infrastructure Engineering. DOI: 10.1080/15732479.2016.1188318

[15] Lannes DP, Gama AL, and Bento TFB (2018) Measurement of flow rate using straight pipes and pipe bends with integrated piezoelectric sensors. Flow Measurement and Instrumentation 60: 208-216.

[16] Mistretta L, Giaconia GC, Valenza A, Napoli E, Gianguzzi C, Presti ML, Di Puma F (2018) Embedded Monitoring Systems for Cured-In-Place Pipes. Applications in Electronics Pervading Industry, Environment and Society, Lecture Notes in Electrical Engineering 429, ed De Gloria A, Springer International Publishing, pp 12-17. DOI 10.1007/978-3-319-55071-8_2 
[17] Kim Y, Schmid T, Charbiwala ZM, Friedman J, Srivastava MB (2008) NAWMS: nonintrusive autonomous water monitoring system. SenSys'08, Nov 5-7, Raleigh, NC, pp 309-321.

[18] Froehlich J, Larson E, Campbell T, Haggerty C, Fogarty J, Patel SN (2009) HydroSense: Infrastructure-mediated single-point sensing of whole-home water activity. UbiComp 2009, Sep 30-Oct 3, Orlando, FL, pp 235-244.

[19] Owojaiye G and Sun Y (2013) Focal design issues affecting the deployment of wireless sensor networks for pipeline monitoring. Ad Hoc Networks 11: 1237-1253. https://doi.org/10.1016/j.adhoc.2012.09.006

[20] Nwalozie GC and Azubogu ACO (2014) Design and Implementation of Pipeline Monitoring System Using Acceleration-Based Wireless Sensor Network. International Journal of Engineering and Science 3(9): 49-58.

[21] Saseendran S and Nithya V (2016) Automated Water Usage Monitoring System. International Conference on Communication and Signal Processing, April 6-8, India, pp 99-103.

[22] Task Force Tips Fire Fighting Equipment Products website, about the Sho-Flow Bluetooth series flow meter, https://www.tft.com/Product-Series/SHO-FLOW-Series

[23] Brown CU, Vogl G, Tam WC (2019) Measuring Water Flow Rate for a Fire Hose Using Wired Accelerometers for Smart Fire Fighting, National Institute of Standards and Technology, Gaithersburg, MD, NIST Technical Note 2075. https://doi.org/10.6028/NIST.TN.2075

[24] Brown CU, Vogl G, Tam WC (2019) Measuring Water Flow Rate in a Flexible Fire Hose using an Accelerometer. Suppression, Detection and Signaling Research and Applications Symposium Proceedings, Sept 17-19, Denver, CO.

[25] Blevins RD (1977) Flow Induced Vibration, Van Nostrand Reinhold Co, Litton Educational Publishing, NY, NY.

[26] AS/NZS 1221:1997 Australian / New Zealand Standard Fire Hose Reels.

[27] IEPE-Link -LXRS Wireless IEPE Sensor Node User Manual (2014) LORD Sensing Systems MicroStrain, Williston, VT.

http://files.microstrain.com.s3.amazonaws.com/IEPELink\%20User\%20Manual\%20(8500-0043).pdf

[28] Orfanidis SJ (1996) Introduction to Signal Processing, Prentice-Hall, Englewood Cliffs, NJ. 
[29] NFPA 1710 - Standard for the Organization and Deployment of Fire Suppression Operations, Emergency Medical Operations, and Special Operations to the Public by Career Fire Departments, 2016 Edition, Section 5.2.4.1, National Fire Protection Association, Quincy, MA.

[30] WSDA-200-USB Wireless USB Base Station User Manual, LORD Sensing Systems MicroStrain, Williston, VT. https://www.microstrain.com/sites/default/files/wsda200_usb_user_manual_8500-0077.pdf 